Portland State University

PDXScholar

Fall 2009

\title{
Effects of Tide Gate Replacement on Water Temperature in a Freshwater Slough in the Columbia River Estuary
}

Sara Ennis

Portland State University

Follow this and additional works at: https://pdxscholar.library.pdx.edu/mem_gradprojects

Part of the Environmental Indicators and Impact Assessment Commons, Natural Resources Management and Policy Commons, and the Water Resource Management Commons Let us know how access to this document benefits you.

\section{Recommended Citation}

Ennis, Sara, "Effects of Tide Gate Replacement on Water Temperature in a Freshwater Slough in the Columbia River Estuary" (2009). Master of Environmental Management Project Reports. 12. https://pdxscholar.library.pdx.edu/mem_gradprojects/12 https://doi.org/10.15760/mem.26

This Project is brought to you for free and open access. It has been accepted for inclusion in Master of Environmental Management Project Reports by an authorized administrator of PDXScholar. Please contact us if we can make this document more accessible: pdxscholar@pdx.edu. 


\section{Effects of Tide Gate Replacement on Water Temperature in a Freshwater Slough in the Columbia River Estuary}

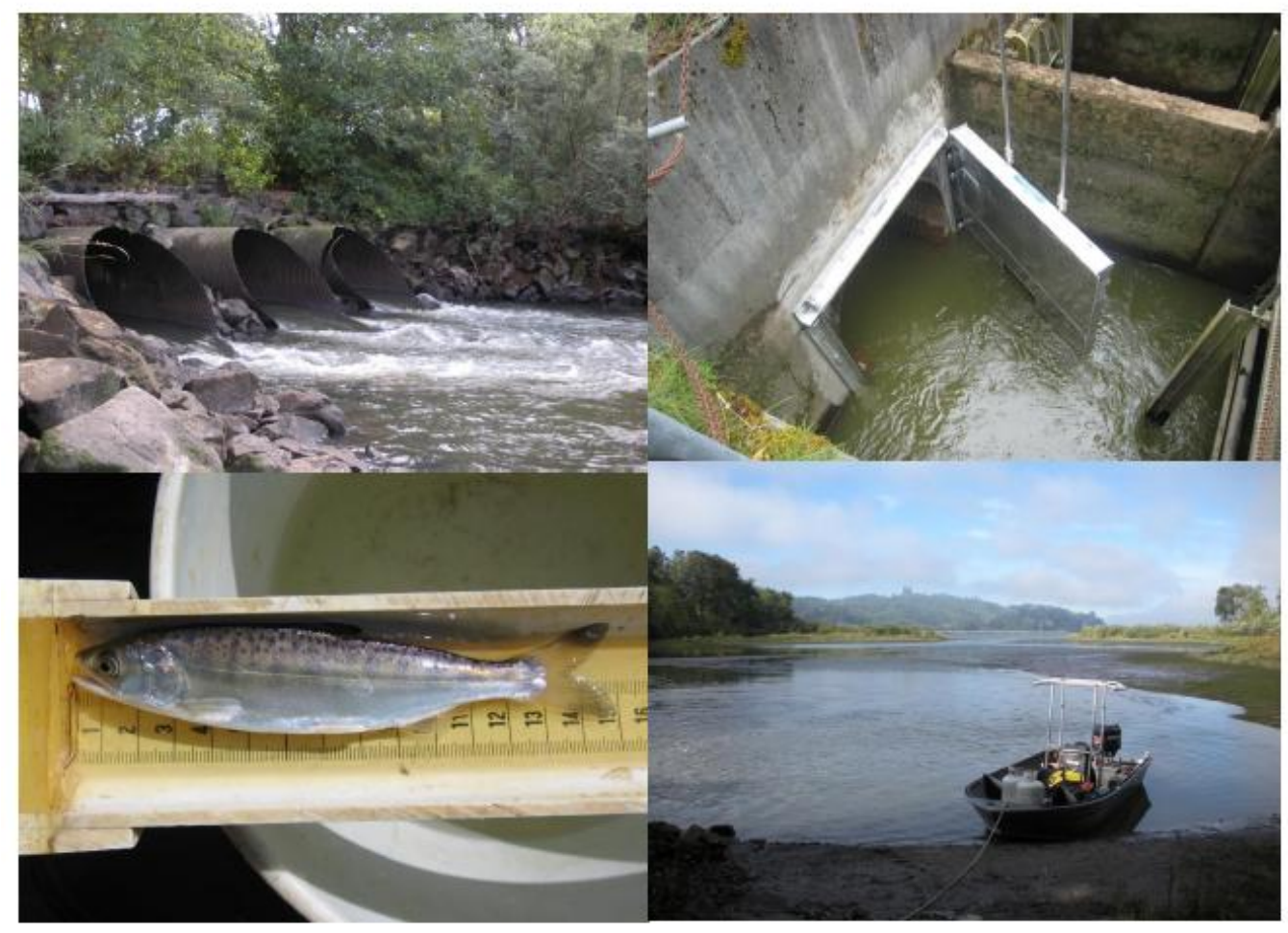

Sara Ennis

Masters Project

Environmental Science and Management

Advisor: Yangdong Pan

Portland State University

Fall 2009 


\section{Acknowledgements}

It is said, "It takes a village to raise a child," and I would add that it takes a community to complete a thesis. I am eternally grateful for friends, family, colleagues and professors who supported and guided me through this process. Thanks to my advisor, Yangdong Pan, for consistent patience and encouragement, to Alan Yeakley for help with analysis and encouragement, and to my colleagues at the US Fish and Wildlife Service, Jeff Johnson and Jennifer Poirier, without whom this project would not have been possible. Thank you! 


\section{Table of Contents}

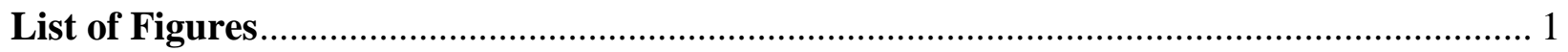

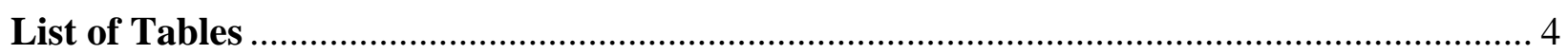

Abstract

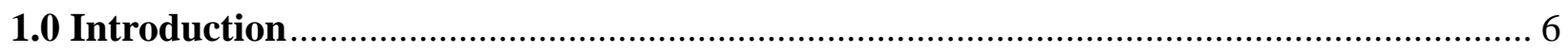

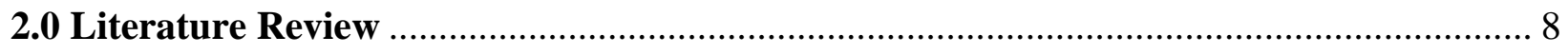

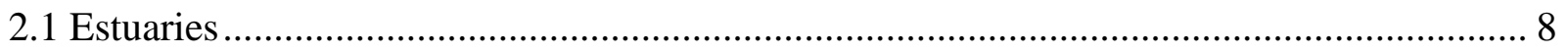

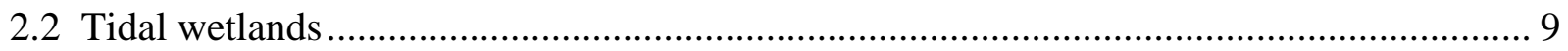

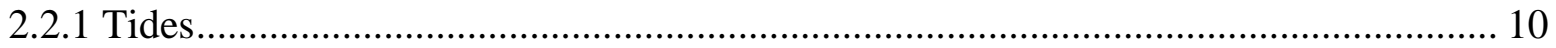

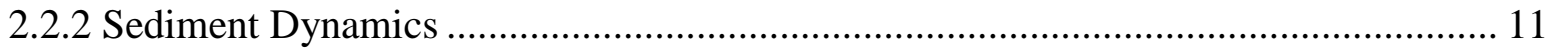

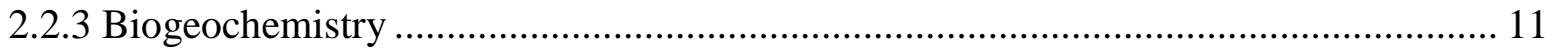

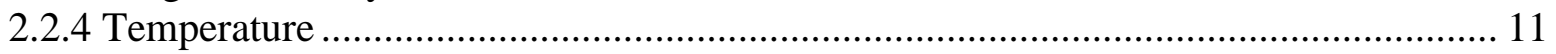

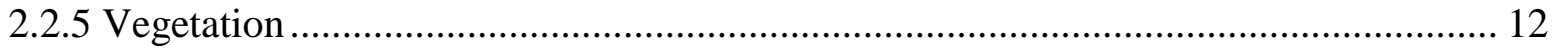

2.3 The Columbia River Estuary and Salmon …………................................................. 13

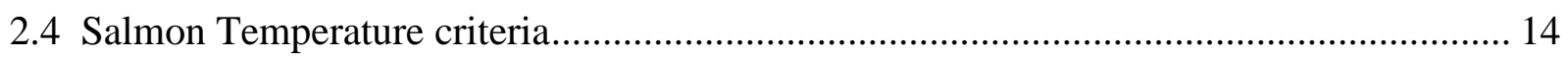

2.5 Effects of Dams on Columbia River Hydrology ....................................................... 15

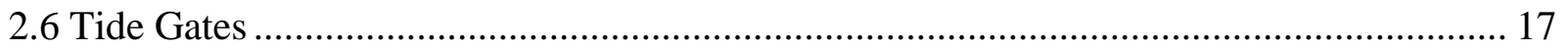

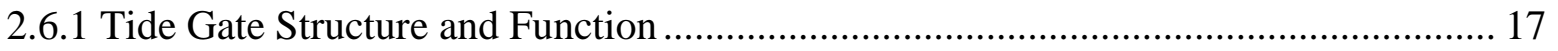

2.6.2 Effects of Tide Gates .......................................................................................... 17

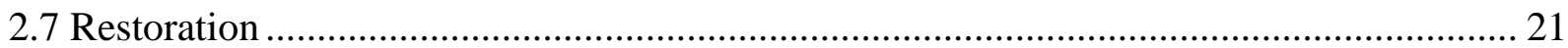

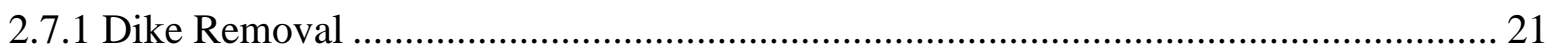

2.7.2 Tide gate replacement .................................................................................... 23

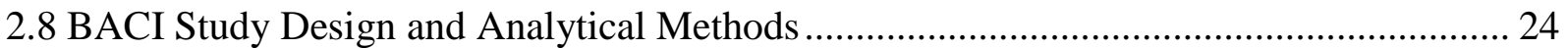

2.8.1 Before-After, Control-Impact ................................................................................... 24

2.8.2 Randomized Intervention Analysis (RIA) …………............................................. 26

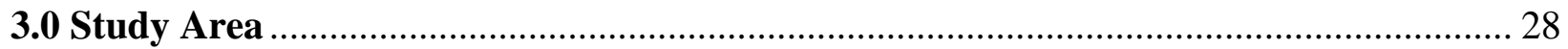

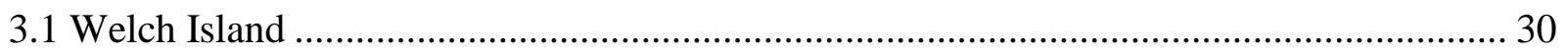

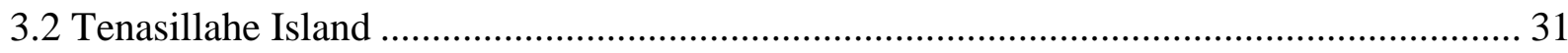

3.3 Tide Gate Replacment, "Restoration” or "Impact".......................................................... 32 


\section{Table of Contents (continued)}

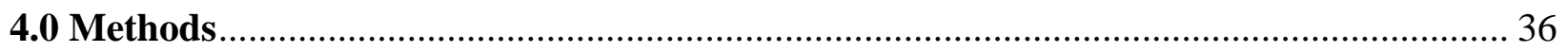

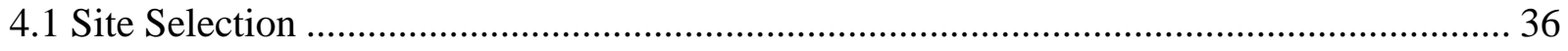

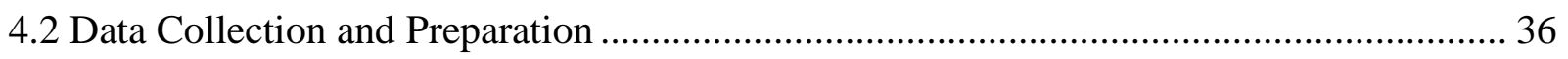

4.3 Study Design: Before-After, Control-Impact …………………………………............ 37

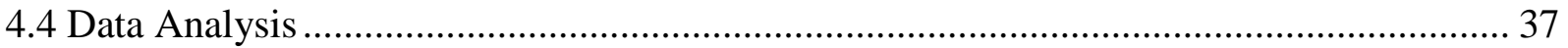

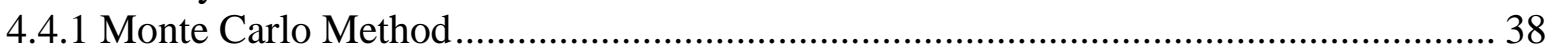

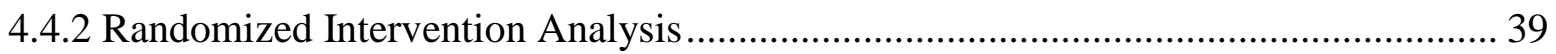

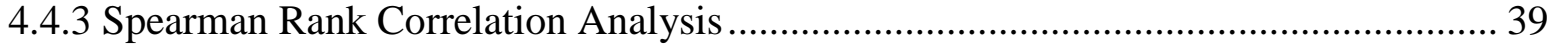

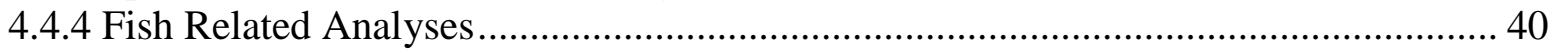

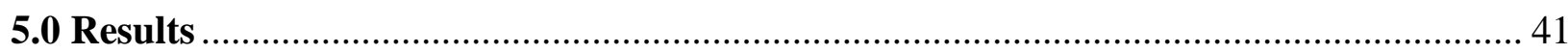

5.1 Effect of Tide Gate Replacement on Water Temperature ................................................ 41

5.2 Effects of Replacement on Fish Habitat in terms of Temperature..................................... 43

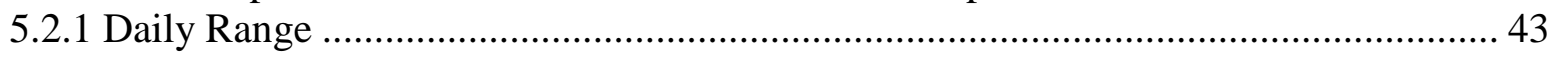

5.2.2 Temperature-Depth ............................................................................................ 43

5.2.3 Temperature Exceedances ............................................................................ 43

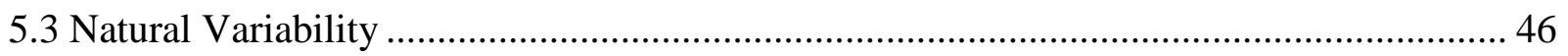

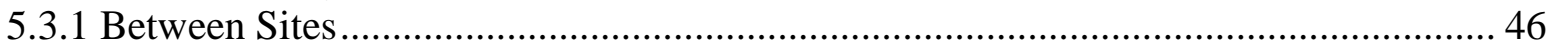

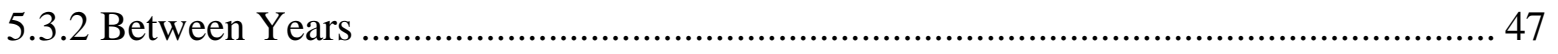

5.4 Other Variables Affecting Temperature …………….................................................... 49

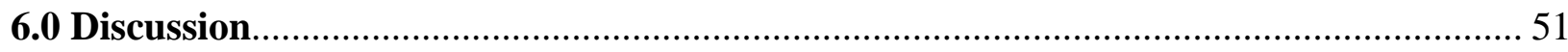

6.1 Effect of Tide Gate Replacement on Water Temperature ................................................. 51

6.2 Effects of Replacement on Fish Habitat in terms of Temperature..................................... 52

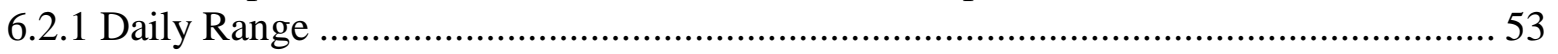

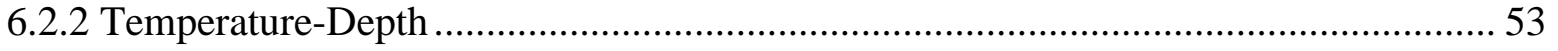

6.2.3 Temperature Exceedances ..................................................................................... 53

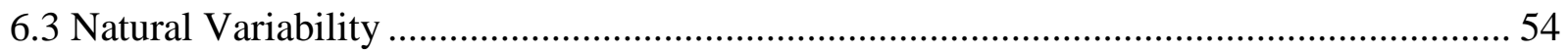

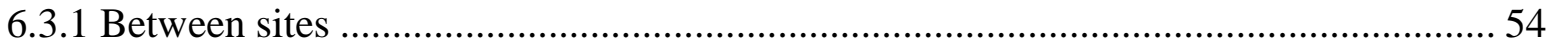

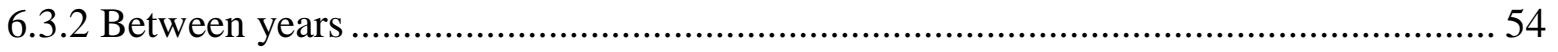




\section{Table of Contents (continued)}

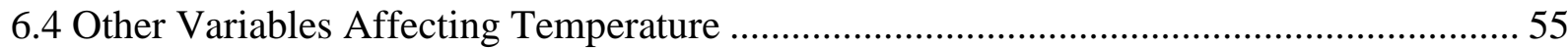

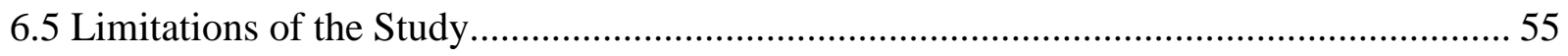

6.6 Management Implications and Recommendations ........................................................... 56

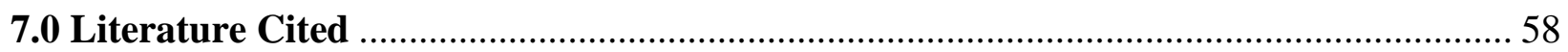




\section{List of Figures}

Figure 1. Illustration of an estuary with a shallow network of channels with full tidal range. From South Slough National Estuary Research Reserve.

Figure 2. A method of classifying estuary habitat by the salinity gradient and location in the estuary from fully Marine (Euhaline) to Non-Tidal Freshwater. The study sites were Tidal Fresh

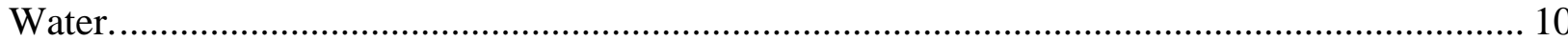

Figure 3. Factors affecting water temperature in Large Tenasillahe Slough. ......................... 12

Figure 4. Illustrates how a network of natural estuarine channels (Figure 1) can be converted to pasture using dikes and tide gates. The tide gate prevents tidal inflow creating a fresh water pasture. Tidal channels are consolidated into ditches and allowed to drain through a tide gate in the dike. From South Slough National Estuary Research Reserve).

Figure 5. Hourly depth data from up (dashed line) and downstream (solid line) of the tide gates in the impact site on Large Tenasillahe Slough. Tide gate openings occur at the intersection of the two depths during the ebb tide when downstream Water Surface Elevation (WSE) drops below upstream WSE during, creating the hydraulic head necessary to open the gate. Gate openings occurred during every low tide during the neap tides until $4 / 10$, when they occurred only during the lower low tide of the spring tide cycle until 4/19. Depth data has not been referenced and so provides only an approximation of tide gate openings.

Figure 6. Lateral view of a culvert placed in a dike with a top hinged tide gate at the downstream end. Higher upstream pool elevation causes the gate to open at low tide. High velocity outflows form a scour pool at the downstream end of the culvert. From Giannico and

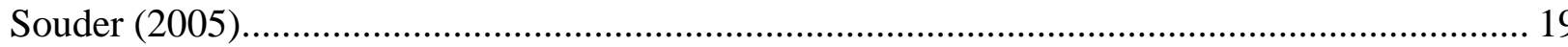

Figure 7. BACI detects a change to an ecosystem by testing the change in the difference between the control and impact sites, before and after an impact, for significance. In figure A, the mean temperature decreased at both the control and the impact sites after the impact.

Because the temperature change affected both sites similarly, and because the difference in mean temperature was similar before and after the impact, the temperature change cannot be attributed to the impact. Figure B illustrates a scenario where the difference in mean temperature between sites increased significantly after the impact. Because the only significant temperature change occurred at the impact site, with additional supporting evidence, the change may be attributed to the impact. From Steward-Oaten (1886).

Figure 8. The study site is located in the Lower Columbia River Estuary, inset upper right. The control site, LWS, is located on Welch Island to the north and downstream of the impact site, LTS, on Tenasillahe Island. Data used for this study were collected at the circled temperature loggers and by the CMOP temp logger 
Figure 9. The mouth of Large Welch Slough. The temperature logger, placed in PVC pipe in the box on the left, is $300 \mathrm{~m}$ from the mouth of the slough

Figure 10. Hourly water surface elevation (WSE) in decimeters (dashed line) and water temperature in ${ }^{\circ} \mathrm{C}$ (solid line) in LWS. Data collected from April $4^{\text {th }}$ to June $13^{\text {th }}, 2008$.

Figure 11. Downstream end of the culverts in the dike on LTS. The data logger is in the PVC pipe in the box on the right. The upstream portion of the slough is behind the trees. Photo taken during ebb tide. Flow at mouth of culverts indicates gates are open. 33

Figure 12. Whereas an unobstructed slough like LWS recharges primarily via tidal inflow, recharge to a gated slough like LTS, occurs via seepage through the dike, precipitation, runoff, and ground water. Water leaves the slough as it drains through the culvert at low tide and through evaporation. If outflow is greater than the rate of recharge, water levels in the slough decrease.

Figure 13. Hourly water surface elevation (WSE) in decimeters (dotted and dashed lines) and water temperature in ${ }^{\circ} \mathrm{C}$ (solid lines) in LTS. Data collected from April $4^{\text {th }}$ to June $13^{\text {th }}$ in 2008.

Figure 14. Top-hinged, cast-iron tide gates (A) on Tensillahe were replaced after the data collection period in 2007 with side-hinged aluminum gates (B) with a manually operated fish orifice (circled) designed to open with lower hydraulic head increasing the frequency, duration and width of openings.

Figure 15. Boxplots of 7-DADM temperatures $\left({ }^{\circ} \mathrm{C}\right)$ before and after tide gate replacement (restoration) for downstream of the tide gates (secondary impact site), upstream of the tide gates (primary impact site), andLWS (control).

Figure 16. Boxplots of 7-DADM temperature $\left({ }^{\circ} \mathrm{C}\right)$ downstream, upstream and in LWS using all data collected from April $4^{\text {th }}$ to June $13^{\text {th }}$ for each year of the study. Tide gate replacement occurred between the 2007 and 2008 data collection periods.

Figure 17. Boxplots of daily temperature range $\left({ }^{\circ} \mathrm{C}\right)$ before and after tide gate replacement (restoration) downstream and upstream of the gates and in LWS. Range was calculated by subtracting the daily minimum from the daily maximum to indicate the degree of temperature fluctuation at each site.

Figure 18 A and B. Hourly temperature $\left({ }^{\circ} \mathrm{C}\right)$ and depth $(\mathrm{dm})$ data from upstream of the tide gates from the data collection period of April $4^{\text {th }}$ to June $13^{\text {th }}$ for 2006 (A) and 2008 (B). Years and sites selected to represent negative and positive correlations (see Table 7).

Figure 19. Number of days 7-DADM temperatures exceeded the EPA $18^{\circ} \mathrm{C}$ non-core summer rearing habitat standard for middle and lower reaches during the data collection period of 71 days between April $4^{\text {th }}$ and June $13^{\text {th }}$ for each site and for each year. The leftmost bar is 
downstream, followed by upstream and LWS. Tide gate replacement (the impact) occurred between 2007 and 2008 .

Figure 20. Time series plot for 7-DADM temperature $\left({ }^{\circ} \mathrm{C}\right)$ values for all years at all sites for the duration of the data collection period. Upstream temperatures are represented with a dashed line, downstream also has longer dashes and LWS is solid. 48

Figure 21. Spearman Rank Correlation matrix for all variables from 2006-2008 (Precipitation data were not available for 2009). The variables are displayed with the distribution of their on the middle diagonal from upper left to lower right: Upstream, downstream, LWS Clifton Channel and air are 7-DADM temperature values $\left({ }^{\circ} \mathrm{C}\right.$ ), daily Columbia River discharge (Cubic Feet per Second) and daily precipitation (in). On the lower left of the matrix, the intersection of two variables displays the correlation plot and the intersection in the upper right indicates the correlation, r-value. Higher r-values are larger indicating a stronger correlation. 


\section{List of Tables}

Table 1. Comparison of size, slough length, tidal range, flood regime, recharge, fish species, vegetation cover, infrastructure, grazing, and baseline water temperature before the impact late in 2007, between Welch Island, the control site, and Tenasillahe Island, the impact site, 28

Table 2. BACI study design including years of data collection before and after the impact and the control and impact sites.

Table 3. Research questions and analytical methods used to address them. 38

Table 4. Summary statistics for 7-DADM temperatures $\left({ }^{\circ} \mathrm{C}\right)$ before and after tide gate replacement and the difference between them for the three study sites: downstream, upstream and LWS.

Table 6. Results from RIA significance test for comparisons between upstream-LWS and downstream-LWS using daily temperature range $\left({ }^{\circ} \mathrm{C}\right)$. Carpenter and others recommend a significance level of $\leq 0.01$ (1989)

Table 7. Spearman Rank Correlation r-values for hourly temperature and depth data collected between April $4^{\text {th }}$ and June $13^{\text {th }}$ of each year downstream, upstream and in LWS.

Table 8. Number of days 7-DADM temperatures exceeded the EPA $18^{\circ} \mathrm{C}$ summer rearing habitat during the data collection period of 71 days between April $4^{\text {th }}$ and June $13^{\text {th }}$ for each site and for each year

Table 9. Results from Monte Carlo significance test for comparisons between upstreamdownstream, upstream-LWS and downstream-LWS using a sample size of 142 7-DADM temperature $\left({ }^{\circ} \mathrm{C}\right)$ values. Data were collected between April $4^{\text {th }}$ and June $13^{\text {th }}$ each year. A pvalue $<0.05$ indicates a significant difference in temperature between sites.

Table 10. Results from Monte Carlo significance test for comparisons between years using a sample size of 1427 -DADM temperature $\left({ }^{\circ} \mathrm{C}\right)$ values for each test. Data were collected between April $4^{\text {th }}$ and June $13^{\text {th }}$ each year. A p-value $<0.05$ indicates a significant difference in temperature between years. 


\begin{abstract}
Dramatic declines in salmon populations in the Pacific Northwest have brought new attention to the importance of estuarine rearing habitats. Levees and tide gates used to convert estuarine wetlands into farmland have reduced available habitat by more than half of historical levels. Recent efforts to restore estuarine habitats include tide gate replacement, though this method has been poorly studied. As a key indicator of salmon habitat suitability, temperature was used to evaluate the effects of tide gate replacement in a tidally influenced freshwater slough in the Lower Columbia River estuary. Three tide gates in the largest slough on Tenasillahe Island were replaced in 2007 with side-hinged aluminum gates. As managed during the data collection periods, the new tide gates did not allow tidal inflow into the slough. The study employed a Before-After, Control-Impact (BACI) approach, collecting data seasonally two years before and after replacement at the impact site and at the control site, a relatively unaltered slough on nearby Welch Island. Randomized Intervention Analysis and Monte Carlo tests revealed no significant difference in slough water temperatures after tide gate replacement, although minimum temperatures dropped up and downstream of the tide gates. Although the new tide gates did not have a significant effect on water temperature, the lower minimum temperatures may have been caused by a slight increase in tidal circulation. This result suggests that slough temperatures would decrease if the tide gates were managed to increase tidal inflow, and thus improve the quality of salmon rearing habitat.
\end{abstract}




\subsection{Introduction}

With major declines in salmon populations across the Pacific Northwest, every aspect of the salmon life cycle and the corresponding habitat needs have come under examination. Recent studies indicate that estuarine wetlands provide critical rearing habitat for juvenile salmon and that adult survival is strongly correlated with time spent in estuarine wetlands (Bottom 2005). Historically considered an inefficient use of land, wetlands have been drained with the use of levees and tide gates for agriculture and development (Giannico and Souder 2005). Oregon has lost over half its historical estuarine wetlands, though legislation in the last few decades has slowed the rate of destruction (Bottom 2005). Unlike dams, culverts or other structures that impede salmon passage and degrade habitat, there is little regulation regarding the management of tide gates, nor are there provisions for mitigating their effects on salmon (Giannico and Souder 2005).

In recent years, greater emphasis has been placed on preserving and restoring salmon habitat, including tidal sloughs adversely affected by tide gates. Specific knowledge regarding the impacts of tide gates and levees on estuarine sloughs and the corresponding effect on juvenile salmon is incomplete. Even greater, is the lack of knowledge of how ecosystems respond to restoration actions. Large scale ecosystem restoration is a relatively new and complex field. Restoration projects are subject to the high variability of numerous environmental factors making it exceedingly difficult to assess the effectiveness of the restoration. Confounding these circumstances is a lack of funding for monitoring so that little new knowledge is gained from each successive project.

Preliminary studies indicate that larger scale restoration actions such as levee removal are more effective at restoring key habitat characteristics than the comparatively small tide gate replacement projects, which make modest improvements at best, or depending on the management strategy, may cause further harm (Coos Bay Association 2006). Different manufacturers have developed "fish friendly" tide gates designed to allow for greater fish passage and tidal exchange, however limited studies have been conducted on their effectiveness in improving conditions (Giannico and Souder 2005). Given the increase in tide gate replacement projects intended to meet salmon passage and habitat requirements, this information is sorely needed. To reduce this knowledge gap, staff from the Columbia River Fish Program 
Office of the US Fish and Wildlife Service have implemented a statistically rigorous BeforeAfter, Control-Impact, study design for the Tenasillahe tide gate replacement project. Data were collected two years before and after tide gates were replaced on Tenasillahe Island in 2007, and on the relatively undisturbed neighboring Welch Island, which served as a control.

The objectives of the study are two-fold. The first set of objectives address biological considerations of salmon passage, abundance and productivity related to tide gate replacement. The second set of objectives address habitat concerns, which is the primary focus of this paper. Several state and federal agencies use temperature as a critical indicator of salmon habitat suitability, because salmon are highly temperature sensitive and have specific temperature thresholds for optimal development at different life stages. I selected temperature as the focus of this study as the most critical abiotic indicator of habitat suitability for juvenile salmonids and for the quality and completeness of the data set. In an effort to discern whether or not tide gate replacement is an effective strategy for the improvement of salmon rearing habitat, I attempt to answer the following questions:

1) Did tide gate replacement affect:

a) slough water temperature?

b) salmon rearing habitat in terms of water temperature?

2) What was the natural variability of temperature between sites and between years?

3) What other factors affect slough temperature? 


\subsection{Literature Review}

\subsection{Estuaries}

An estuary is "an inlet of the sea reaching into the river valley as far as the upstream limit of the tidal rise" (Fairbridge 1980). Estuaries are known as some of the most ecologically productive ecosystems in the world (MacBroom 2008, Williams and Zedler 1999, Mitchell and others 2005) due to the mixing of freshwater and marine nutrients (Agardy and others 2005, Oberrecht 2002). The unique saltwater, brackish and tidally influenced freshwater wetland habitats found in estuaries host diverse flora and fauna providing nursery grounds for many fish, plant and wildlife species. Estuaries also provide ecosystem services like flood control, erosion protection, and water quality enhancement (Frenkel and Morlan 1991, Brophy 2005).

Due to the high productivity and easy access to water based transportation, large port cities and intensive agriculture often occur in estuaries causing severe degradation (Barendregt and others 2006). Because of their position low in the watershed, and the lack of current during slack tides, estuaries become a depository for upstream pollutants (Rheinhardt 2007). Undisturbed estuaries have a high capacity for sequestering heavy metals and other contaminants, however disruption of flow regime alters the biogeochemistry of the system, such that toxins may be released rather than stored (Portnoy 1999). Flow altering structures including dams, dikes, and tide gates, cause the greatest disturbance by decreasing the extent of the tidal prism (Brophy 2005) and consequently reducing the availability of critical wetland and floodplain rearing habitat for fish and wildlife. 


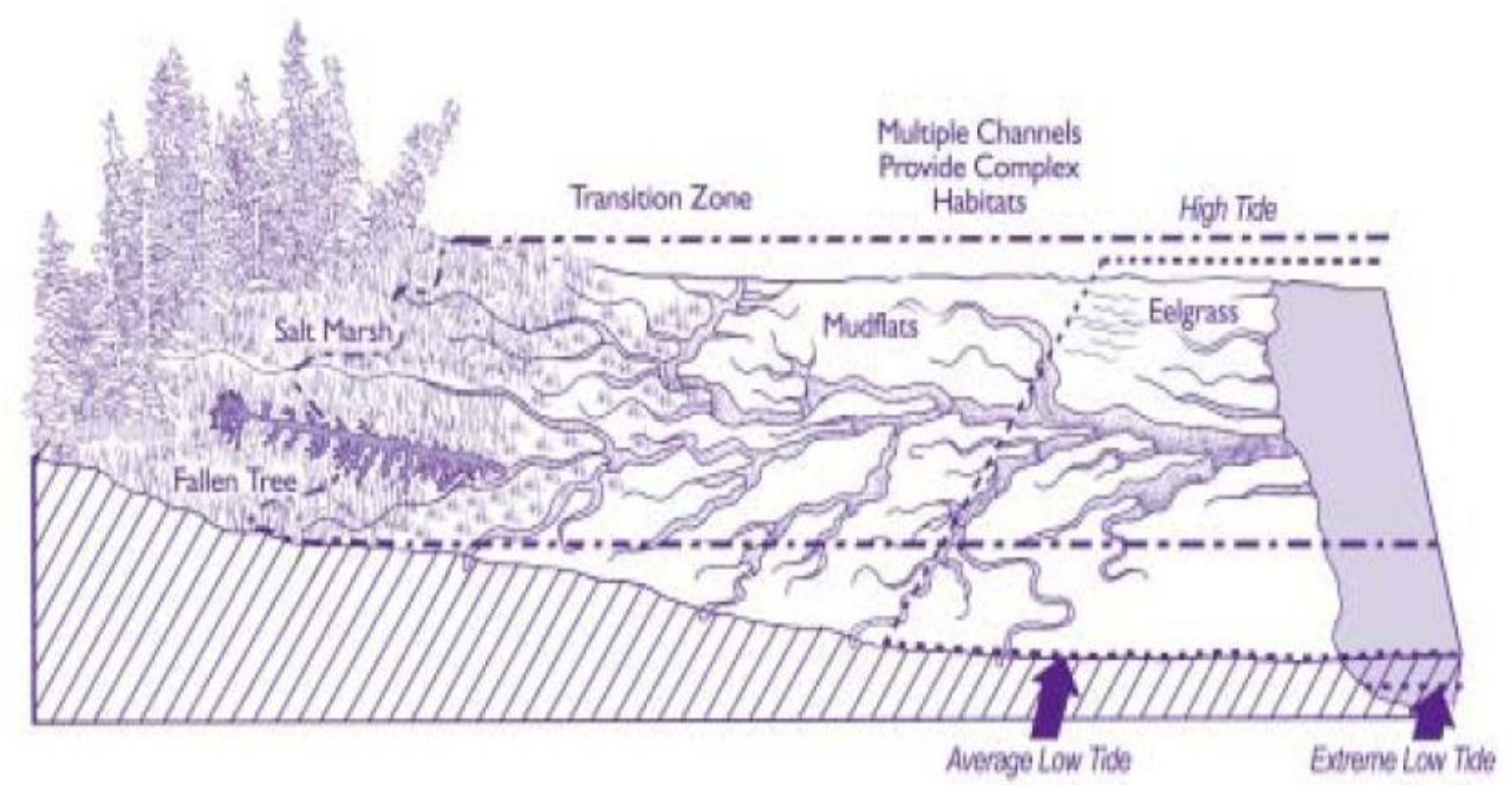

Figure 1. Illustration of an estuary with a shallow network of channels with full tidal range. From South Slough National Estuary Research Reserve.

\subsection{Tidal wetlands}

Little research has been conducted in freshwater tidal wetlands, the uppermost zone in the estuary, due to a lack of unique species in these systems and a lack of overlap between the disciplines of marine and wetland ecology (Barendregt and others 2006). Freshwater tidal wetlands lie low in the valleys of large river basins and are formed by overflow from the main channel into the floodplain and by small tributaries, or sloughs, that flow into the mainstem (Rheinhardt 2007). The location and extent of tidal wetlands depend on the equilibrium between water volume and velocity of fluvial discharge and incoming tides (Barendregt and others 2006) as well as land surface elevation (Neckles and others 2002). Upstream tidal influence is reduced during peak runoff in winter and spring, and increases during low flows in summer and autumn (Barendregt and others 2006).

The extent of tidal wetlands is also partially determined by channel dimensions; narrower channel mouths funnel tides farther upstream (Rheinhardt 2007). Channel geometry is maintained by a dynamic equilibrium between fluvial and tidal erosion and depositional rates (Williams and others 2002). To classify as a freshwater tidal wetland, freshwater runoff flowing 
into the system must exceed the volume of brackish or saline waters (Jones and Kelso 2008), salinity levels must be less than 1\% (Simpson and others 1983, Seybold and others 2002), and the land area must be inundated by tidal waters daily, seasonally or at least annually (Brophy 2005). See Figure 2 for a general illustration of the location of tidal wetlands in the estuary.

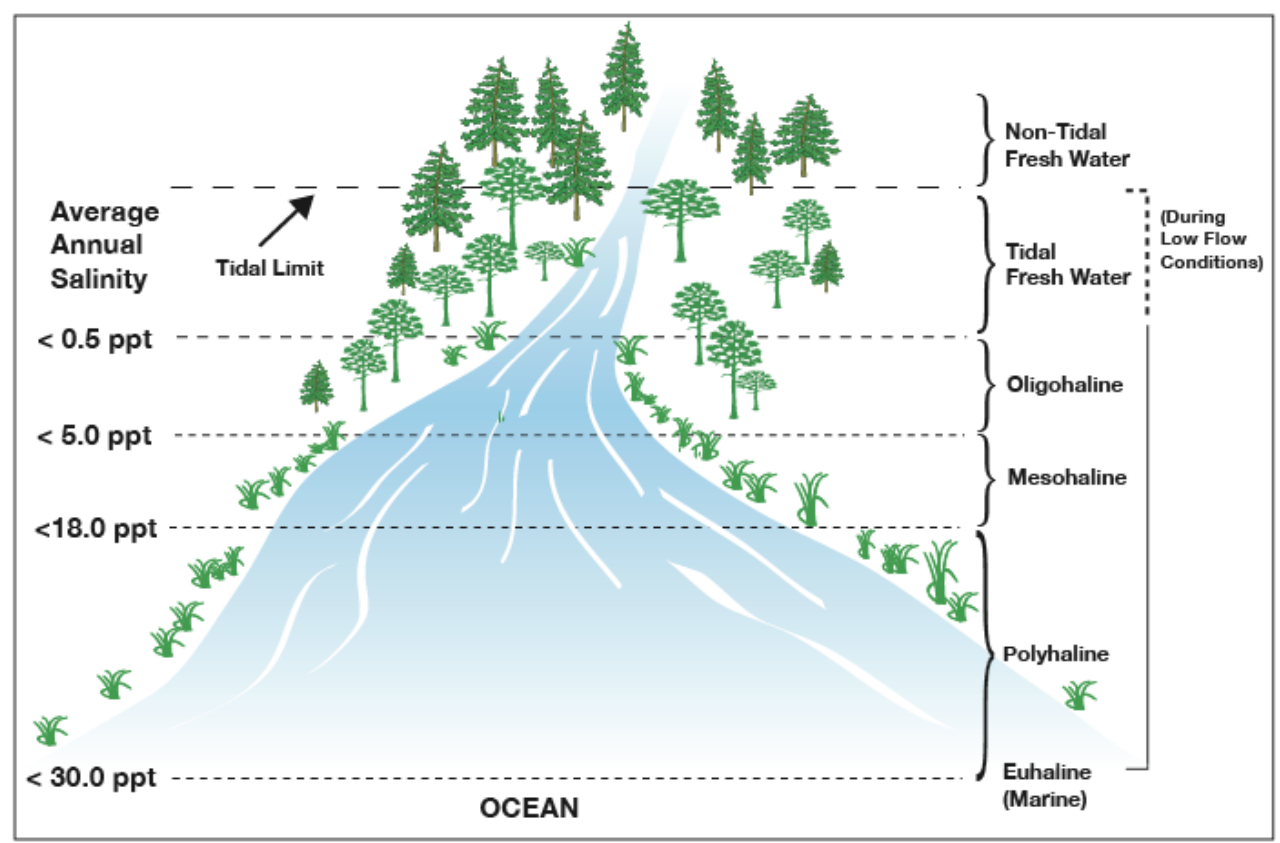

Figure 2. A method of classifying estuary habitat by the salinity gradient and location in the estuary from fully Marine (Euhaline) to Non-Tidal Freshwater. The study sites were Tidal Fresh Water.

From http://coastalscience.noaa.gov/documents/rmv2/Ch10Bundle.pdf

\subsubsection{Tides}

Tides in many freshwater zones are asymmetrical with a brief, high velocity flood tide and a long ebb tide with a tidal range as high as six meters (Barendregt and others 2006). The height and velocity of incoming tides and freshwater runoff also determine the degree of mixing and nutrient exchange. Greater mixing occurs with the greater tidal range during the spring tides (Jones and Kelso 2008). The higher highs and lower lows of the spring tides are caused by the increased gravitational pull of the moon in alignment with the sun during the full and new moons. Neap tides occur during the first and third quarter of the lunar cycle, when the moon is out of alignment with the sun and the opposing gravitational forces of the sun and moon moderate the height of the tides (NOAA 1998). Spring tides cause greater temperature and water quality fluctuations and extremes, particularly on warm summer days, due to the greater extremes of the high and low tides (Beck and others 2001). Temperature and water quality 
parameters must be measured at high frequencies to capture daily and monthly variability and accurately interpret long term trends (Park and Park 2000, Lucas and others 2006).

\subsubsection{Sediment Dynamics}

Freshwater wetlands are known as the "maximum turbidity zone" due to the high influx of sediment from upstream sources (Barendregt and others 2006). These moderate levels of turbidity shelter juvenile fish from predation (Korstrom and Birtwell 2006, Gregory and Levings 1998). Tidal wetlands experience high deposition due to the lack of current during the slack tide and abundant sediment supply. Because of the high deposition rates, the estuary serves as a filter, trapping and preventing upstream contaminants from reaching the sea. The sequestration of contaminants through deposition, the naturally high nutrient and low salinity levels contribute to the high productivity of the freshwater wetlands (Barendregt and others 2006). Tidal wetlands with sinuous channels, overhanging vegetation and undercut banks provide sources of detritus and habitat for invertebrates and high quality forage for juvenile salmonids (Bottom and others 2005).

\subsubsection{Biogeochemistry}

Organic matter in tidal wetlands primarily decomposes via anaerobic processes due to extended periods of inundation. Decomposition in salt marshes occurs primarily via sulfate reduction due to the abundant supply of sulfate from the sea. In tidal wetlands, methanogenesis is the dominant metabolic process (Odum 1988), due to the lack of sulfate in freshwater systems (Schlessinger 1997). Sulfate reducing bacteria are more efficient at using hydrogen as an electron donor than the bacteria performing methanogenesis, consequently, sulfate reduction is the dominant process in the presence of sulfate. The two decomposition processes occur in distinct zones, although they may occur in the same vertical profile. For example, sulfate reduction may dominate in the top few centimeters of soil followed by methanogenesis in the lower soil layers where sulfate is either absent or consumed (Schlessinger 1997).

\subsubsection{Temperature}

Figure 2 illustrates factors that influence slough water temperature. Several of these factors may cause an increase or a decrease in temperature, depending on the specific conditions. Solar radiation will consistently raise temperatures and cause evaporation. Substrate temperature is seldom an important factor, except when sun-baked mud flats heat the flood tide as it 
recharges the slough (Beamer and LaRock 1998). When the substrate remains submerged, the incoming tide recharges the slough with cooler water. Other sources of recharge include runoff, precipitation and ground water, which generally have a cooling effect. Shallower, natural sloughs experience high temperature fluctuations. These sloughs have a higher width to depth ratio and heat up faster than deeper sloughs and cool off quickly as they drain and recharge with each tide cycle. Turbidity from erosion absorbs solar radiation, warming the slough. Land use practices that protect overhanging riparian vegetation tend to maintain cooler temperatures (Tonkin 2009), whereas practices that alter slough morphology and introduce the impacts of agriculture, tend to increase temperatures.

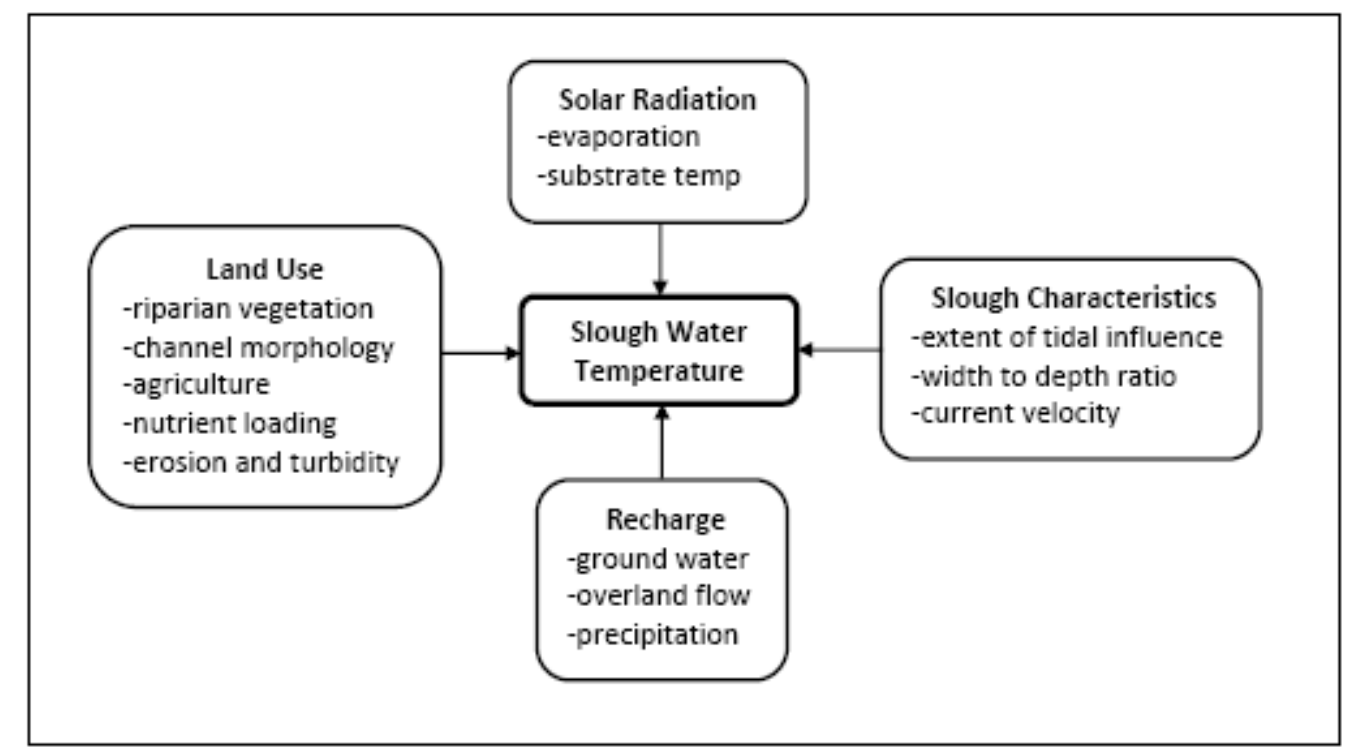

Figure 3. Factors affecting water temperature in Large Tenasillahe Slough.

\subsubsection{Vegetation}

Plant communities are critical for providing both food and shelter to most organisms sheltered in the estuary. The type of plant community is largely determined by the degree of tidal influence. Plant species composition in a tidal wetland is largely determined by the degree of tidal influence and by soil surface elevation (Wetzel and Kitchens 2007). Higher elevations are positively correlated with greater plant density (Cornu and Sadro 2002), woody plants (Barendregt and others 2006) and more advanced stages of succession (Crooks and others 2002). Historically, emergent vegetation dominated most of the tidal wetlands in the Columbia River Estuary, although most of these areas have since been converted to upland shrub and tree communities by human activities (Johnson and others 2003). As the base of the food chain, the 
plant community composition influences what invertebrates are available for salmon forage. Salmon also depend on riparian vegetation to provide shade and habitat structure.

\subsection{The Columbia River Estuary and Salmon}

The Columbia River forms the largest of Oregon's estuaries, draining a basin of 660,500 square kilometers and is dominated by the river's freshwater flow with an average annual discharge of 5,500 cubic meters per second at the mouth (NPCC 2005, Bottom and others 2005). Though the tidal influence reaches $235 \mathrm{~km}$ upstream to Bonneville dam, the salinity gradient dissipates by river kilometer 48, even at low flows (Bottom and others 2005). The freshwater nature of this system distinguishes it from other Oregon estuaries in that only a small fraction of the habitat is salt marsh; most is freshwater tidal wetlands (Good 1999). The Columbia River Estuary has lost $77 \%$ of its tidal habitat due to development and hydrological modifications. (Diefenderfer and others 2005, Brophy 2005, Good 1999).

Historically, five kinds of salmon and two kinds of anadromous trout, collectively known as salmonids, were found in the Columbia River Basin: Chinook (Oncorhynchus tsawytscha), Coho (Oncorhynchus kisutch), Chum (Oncorhynchus keta) Sockeye (Oncorhynchus nerka), Pink (Oncorhynchus gorbuscha), and sea-run Rainbow Trout, or Steelhead, (Oncorhyncus mykiss) and sea-run Cutthroat Trout (Oncorhyncus clarki). Currently, the returning runs of Coho and Chinook are the largest; Sockeye and Chum populations are rapidly dwindling and Pink are mostly extirpated from the Basin. Most runs of native Steelhead and sea run Cutthroat are also listed (Bottom and others 2005). At peak levels in the early 1900's, up to 16 million adult salmon returned to the basin annually. By the 1990's, populations were reduced to 1.5 million (NPCC 2005), 80\% of which were of hatchery origin (Bottom and others 2005). Population reductions are due primarily to habitat loss, dam related mortalities, and overharvest. More than 13 Evolutionarily Significant Units (ESUs), or distinct salmon populations, are listed as threatened or endangered in the Columbia Basin (Diefenderfer and others 2005). Due to numerous recovery efforts, populations have increased to 3 million fish returning each year, $70 \%$ of which are hatchery (Paquet, personal communication).

Historically, estuaries were considered an insignificant migratory corridor, or worse, a bottleneck increasing the risk of predation for juvenile fish. More recent studies indicate the estuary provides critical rearing habitat for many salmonid species (Bottom 2008). Salmon pass through the estuary twice over the course of their life cycle, during out- and in-migration. 
During the outmigration period, the estuary provides juveniles with abundant food resources (Shreffler 1992), refuge from predators, and a gradual transition between fresh and salt water for the process of smoltification (Bottom and others 2005, Brophy 2005). The greater the tidal range, the wider the extent of available habitat, reducing competition (Tonnes 2007). Wetland foraging increases juvenile growth rates, and improves early ocean survival, by increasing overall fitness and reducing risk of predation due to their larger size (Oberrecht 2002, Brophy 2005, Miller and Simentstad 1997). Consequently, time spent in the estuary as a juvenile is correlated with higher adult return rates (Bottom and others 2005).

Depending on the species, juveniles remain in the estuary from two weeks to eighteen months, although salmon are present in the estuary year round. Salmon with different lifehistory strategies have different habitat needs, and needs of individual ESUs differ depending on the developmental stage. In general, fry and fingerlings tend to reside in small, shallow habitats while smolts forage in larger, deeper waters (Bottom 2008). A study on Chum in the Skagit River Estuary in Washington indicated that juveniles fed most intensely during high tide on prey associated with wetlands inundated to depths of 0.3 to 1.0 meters (Beamer and LaRock 1998). Estuarine habitat diversity is critical to all salmonid ESUs, regardless of estuarine residence time. The salmonid homing instinct is informed by olfactory signals generated by a sequence of environmental gradients as they migrate through the estuary during parr-smolt transformation. These signals are created by watershed scale processes and functions. The disruption of habitat sequence and the reduction of habitat diversity reduces salmon fitness and diversity (Bottom and others 2005). Because of the high salmon productivity associated with estuaries, restoring estuarine habitats is a high priority in salmon recovery efforts (Bottom and others 2005).

\subsection{Salmon Temperature criteria}

Salmon display broad genetic flexibility in their physiological, behavioral, morphological and developmental capacity, which has allowed them to inhabit diverse ecosystems throughout the northwest (Sauter and others 2001). Individual stocks (ESUs) are adapted to specific habitats and have a narrower range of habitat requirements. Of these habitat requirements, temperature is the key abiotic indicator of suitability. Temperature is influenced by such factors as channel complexity, riparian cover, ground water influence, and thermal gradients (Richter and Kolmes 2005). Within a habitat, salmon thermal regulate by moving to parts of the habitat that meet their temperature needs (Pool and others 2001). This is particularly important in summer, when 
salmon seek pockets of cooler water, known as thermal refugia. Human alterations to hydrology and channel structure can reduce the availability of refugia by increasing overall temperatures and creating thermal migratory barriers through which salmon cannot pass without suffering lethal or sub-lethal effects (Sauter and others 2001).

The developmental stages when salmon are most sensitive to high temperatures are egg through smolt, and spawning, when temperature increases of $2-3^{\circ} \mathrm{C}$ can reduce fitness and productivity (Pool and others 2001). Optimal rearing temperatures range from $12-17^{\circ} \mathrm{C}$ with $15^{\circ} \mathrm{C}$ being the optimal upper limit, although thresholds vary depending on the species (Richter and Kolmes 2005). The EPA indicates the upper temperature limit for core-rearing habitats is $16^{\circ} \mathrm{C}$, non-core rearing habitats is an $18^{\circ} \mathrm{C}$ Seven Day Average Daily Maximum (7-DADM), and $20^{\circ} \mathrm{C}$ is acceptable for migration corridors (EPA 2003).

Because salmon metabolic rates increase with higher temperatures, slightly warmer water can increase salmon growth and subsequent fitness, given an ample food supply (Pool and others 2001). Lacking adequate forage, juveniles prefer cooler temperatures. At temperatures above the upper limits, juveniles experience sublethal effects such as compromised immune systems and greater susceptibility to predation. Higher temperatures may also spur early migration or interfere with enzymatic processes, causing a loss of migratory behavior during smoltification (Sauter and others 2001). Lethal temperatures start in the low $20^{\prime} \mathrm{s}^{\circ} \mathrm{C}$ though some species at different stages of development can survive up to a week in $23-24^{\circ} \mathrm{C}$ water (Poole and others 2001) and briefer exposures to water temperatures of $25^{\circ} \mathrm{C}$ (Richter and Kolmes 2005).

\subsection{Effects of Dams on Columbia River Hydrology}

The Columbia River is a highly engineered system and the hydrology has been fundamentally altered from historical conditions by the construction of dams (Diefenderfer and others 2005). Dams have caused changes in flow regime and reduced habitat availability (Brophy 2005) and a corresponding reduction in the diversity of salmon life-history types in the Basin (Bottom and others 2005). With 14 major dams and numerous smaller dams in the Columbia River Basin, salmon passage is completely blocked upstream of Chief Joseph Dam on the mainstem, and Hells Canyon Dam on the Snake River, reducing habitat availability in the basin by $55 \%$ of historical levels (NPCC 2005). Though salmon populations were in decline as a result of over-harvest prior to the height of dam construction in the 1960's, there has been a marked decline since then with $15 \%$ juvenile mortality at each dam. Retrofits have reduced 
dam-related salmon mortalities to $8 \%$ per dam (Smith 2007). Besides being a direct cause of mortality, dams have adverse effects on habitat quality and quantity. Dams homogenize habitat, reducing diversity and thermal refugia, and regulated flows interfere with historical salmon migration patterns (Diefenderfer and others 2005).

Flow modifications resulting from dam operations include changes in timing and volume of peak flows. Runoff from the Canadian portion of the Columbia River Basin historically accounted for approximately $50 \%$ of the discharge at the Dalles, though only $25 \%$ of the watershed is in Canada (Bottom and others 2005). Since 1970, runoff for "spring freshets," (higher flow events as a result of melt off) has decreased by $40 \%$ due to water retention behind dams (Bottom and others 2005). Freshets now last from three to six months, rather than 30-60 days under historical conditions, increasing the travel time of ocean-bound salmon (Johnson and others 2003). Runoff from the winter and spring freshets recharges reservoirs, and stored water is released during the low flows of summer and fall for irrigation and shipping, potentially impeding the progress of the return migration. Flow management has flattened the historical hydrograph, increased up- and downstream salmon migration times, created water quality problems, and reduced availability of suitable habitat (Sauter and others 2001, Richter and Kolmes 2005).

Other dam related factors reducing habitat quality and access include: irrigation withdrawals, flood plain disconnection, sediment dynamics and poorly constructed fish passage. Permits for water withdrawals reduce available flows and have been issued for up to $20 \%$ of the annual discharge, although this volume is seldom reached (National Research Council 2004). Nevertheless, withdrawals jeopardize salmon by diverting them up irrigation ditches and exposing them to toxic levels of chemical fertilizers and pesticides (Bottom and others 2005). Dikes and flow regulation prevent overbank flow, effectively disconnecting wetland habitats from the main channel, reducing shallow water habitats by $81 \%$ (Bottom and others 2005) and blocking access to remaining habitats.

Sediment dynamics have also been altered by dam construction in the Columbia River. Each dam acts as a sediment trap, removing sediment load from down stream flows. The lack of suspended sediment increases the energy of spring flows (Murphy and Voulgaris, 2006), eroding unprotected banks downstream (Cornu and Sadro 2002). While dams remove sediment, dredging and filling activities increase sediment loads and turbidity with adverse effects on water 
quality (Bottom and others 2005). Absent or inadequate fish passage structures at dams interfere with both down and upstream salmon migrations. Juveniles migrating downstream must either pass through the turbine, the spillway or a specially designed bypass system. For salmon migrating upstream, Fish ladders provide a long series of short leaps to ascend dams, however the lack of resting pools reduces the rate of successful passage (NPCC 2005).

\subsection{Tide Gates}

\subsubsection{Tide Gate Structure and Function}

The primary function of tide gates is to block the inflow of tidal water into upland areas and to protect farmland and development (Figure 3). The first known tide gates were made in Holland circa $175 \mathrm{BCE}$ out of hollowed logs and a wooden flap for a gate (Barendregt and others 2006). Heavy $19^{\text {th }}$ and $20^{\text {th }}$ century models, typically hinged at the top, were made of cast iron or wood and placed at the downstream end of a culvert built into a flood control levee (Giannico and Souder 2005). Acting like a one-way valve, the gates remain closed against the pressure of incoming tides and open due to the hydraulic pressure of water accumulated behind the gate as the tide ebbs (Figure 4). Due to the weight and hinging position of traditional tide gates, the gates are closed by default, or more than $75 \%$ of the time, opening briefly once or twice a day under high pressure (Giannico and Souder 2005). Consequently, tide gates have a significant effect on slough hydrology, sediment dynamics, water temperature, fish passage and vegetation composition, and land use practices.

\subsubsection{Effects of Tide Gates}

\subsubsection{Hydrology}

The hydrology of the Columbia River Estuary directly affects tide gate operation; tides are the primary driver, followed by river stage. Figure 5 provides a hypothetical example of Water Surface Elevation (WSE) up and downstream of the tide gates in Large Tenasillahe Slough (LTS). Tide gate openings typically occurs near the intersection of up and downstream WSE during the ebb tide. Just past the intersection point, downstream WSE drops below the upstream WSE creating the hydraulic head necessary to open the gate. This occurs twice a day during the more even tides of the neap cycle from 4/4 to 4/10. During the varied heights of the spring tides from 4/11 to 4/19 in Figure 5, tide gates may open only once a day if the height of 


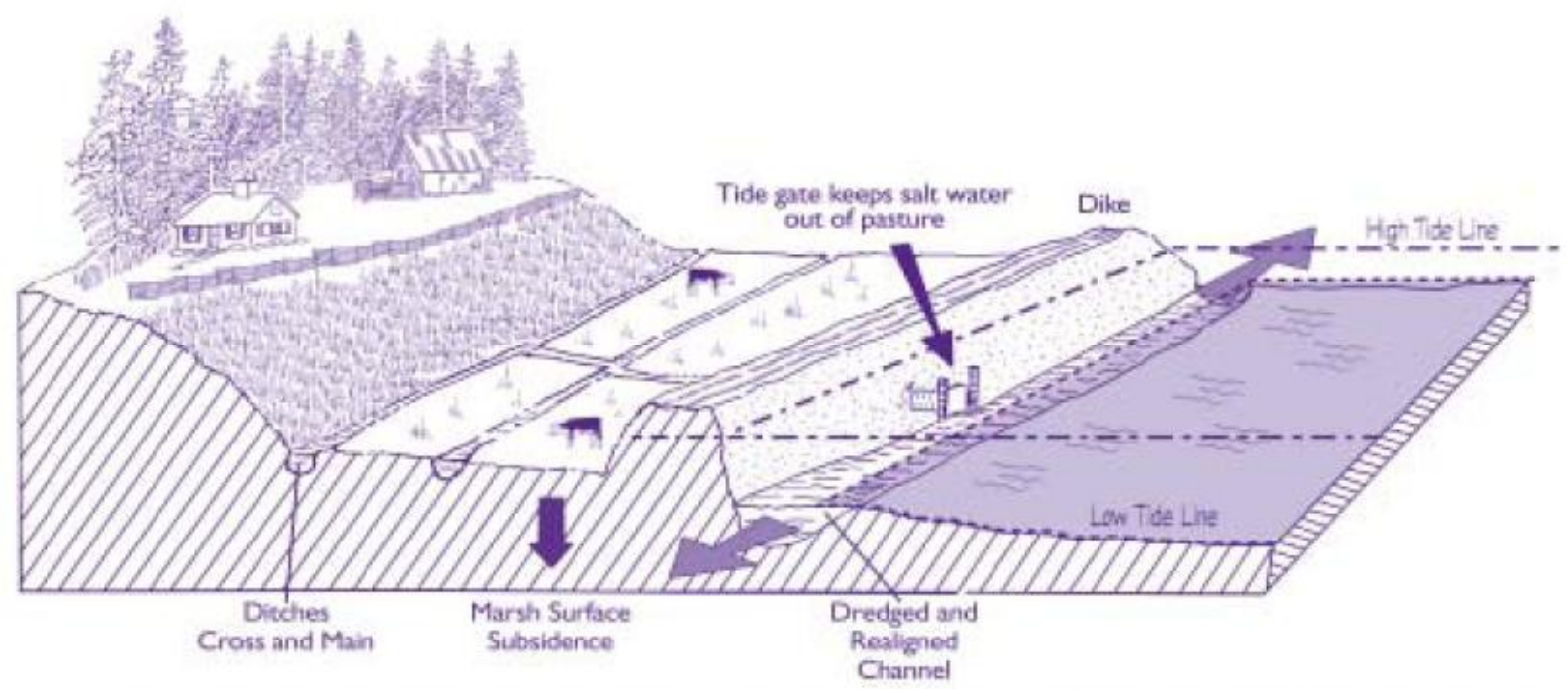

Tidal circulation was lost when estuaries were diked and drained for human activity during the last century.

Figure 4. Illustrates how a network of natural estuarine channels (Figure 1) can be converted to pasture using dikes and tide gates. The tide gate prevents tidal inflow creating a fresh water pasture. Tidal channels are consolidated into ditches and allowed to drain through a tide gate in the dike. From South Slough National Estuary Research Reserve)

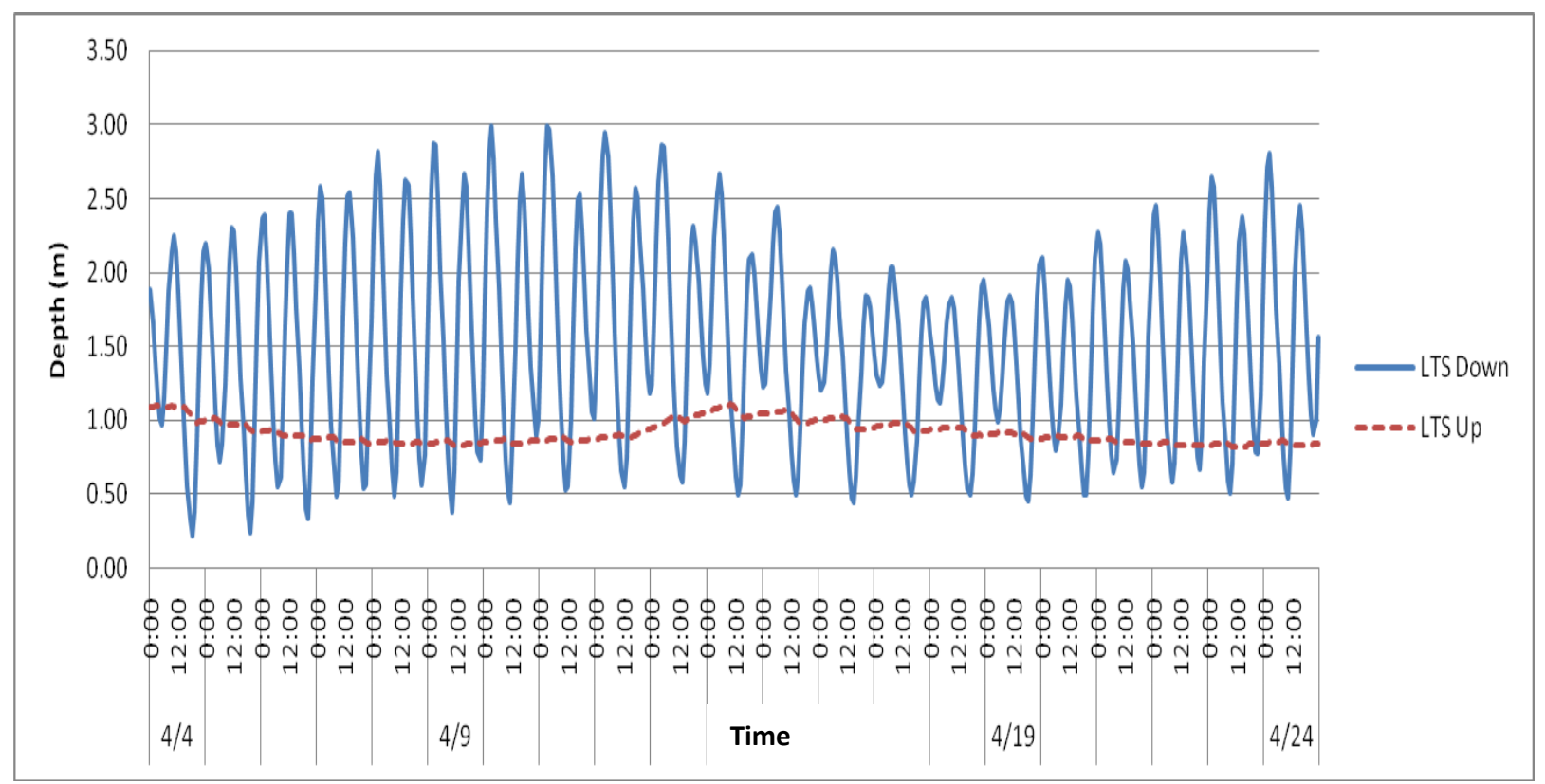

Figure 5. Hourly depth data from up (dashed line) and downstream (solid line) of the tide gates in the impact site on Large Tenasillahe Slough. Tide gate openings occur at the intersection of the two depths during the ebb tide when downstream Water Surface Elevation (WSE) drops below upstream WSE during, creating the hydraulic head necessary to open the gate. Gate openings occurred during every low tide during the neap tides until 4/10, when they occurred only during the lower low tide of the spring tide cycle until 4/19. Depth data has not been referenced and so provides only an approximation of tide gate openings. 
the second low tide remains above the upstream WSE. Frequency of tide gate opening is also affected by seasonal conditions. When low water levels in late summer coincide with spring tides, the gates may not open for a period of days. Conversely, especially high water levels may submerge the gate and prevent them from opening (Maris and others 2007). This is most likely to occur during high flows when the dikes and tide gates intended to protect against flooding exacerbate flood conditions by preventing drainage (MacBroom 2008).

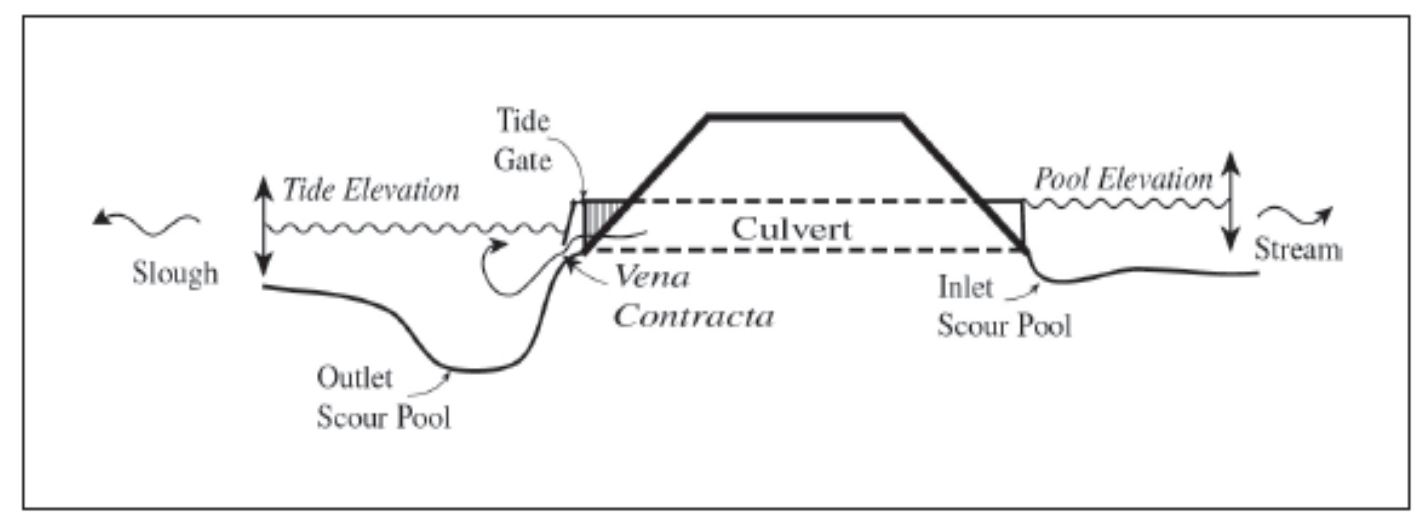

Figure 6. Lateral view of a culvert placed in a dike with a top hinged tide gate at the downstream end. Higher upstream pool elevation causes the gate to open at low tide. High velocity outflows form a scour pool at the downstream end of the culvert. From Giannico and Souder (2005)

Between each opening, slough water levels upstream of the tide gate must recharge sufficiently to create the hydraulic pressure required to open the gate at the next low tide. Immediate sources of recharge include seepage and direct inflow. During the flood tide, higher water surface elevation downstream of the tide gate creates a hydraulic head that causes seepage upstream through the dike, recharging the slough (Johnson, personal communication). Failing tide gates allow direct inflow, as do many new tide gates via a small opening or self-regulating mechanism if managed to do so (Giannico and Souder 2005). The absence of direct tidal inflow typically causes the water table to drop (Tonnes 2007) altering plant species composition and muting the tidal influence upstream of the gate (Osler and others 2007). More delayed sources of recharge include: precipitation, upland runoff and ground water. The rates at which these sources recharge the slough are subject to weather and season, land use practices, and geology (Charland 1997). 


\subsubsection{Sediment}

Dike and tide gated systems also fundamentally alter slough sediment dynamics and biogeochemistry. To maximize dry land for farming and development, networks of shallow tidal channels are typically consolidated into deeper, single channeled systems (Brophy 2005). Upland sediments historically deposited throughout the system during inundation periods are concentrated in the main channel, increasing turbidity and ultimately settling out in the slack water upstream of the gate. The sediment deposited in the channel accretes far upstream altering the surface level elevation and depriving the floodplain of its customary sediment supply (Porior 2003). Land use practices such as grazing cause soil compaction and subsidence (Cornu and Sadro 2002). The effects of compaction are confounded by reductions in soil volume as previously submerged organic material in the soil is exposed to the atmosphere, increasing the rate of decomposition (Turner and Lewis 1997). Atmospheric exposure also changes the soil biogeochemistry. Sulfides in the soil may oxidize and form sulfuric acid, leaching heavy metals stored in the soil (Portnoy 1999, Anisfeld and Benoit 1997). Subsidence and channel consolidation increase the frequency and extent of flooding (Frenkel and Morlan 1991), potentially increasing the area affected by toxicity in the soil.

\subsubsection{Fish and Vegetation}

Tide gates form a physical barrier to fish passage and create an abrupt transition in temperature and flow regime between up and down stream conditions. When closed, tide gates obstruct fish passage and water exchange, reducing habitat access and quality (Tonnes 2007). The sudden changes in flow velocity in tide gated systems can be detrimental, forcing juvenile salmon from an optimal low velocity rearing environment, prematurely into the main channel where they are exposed to compromising flow conditions, sub-optimal forage, and a greater threat of predation. Closed gates and high velocity flows prevent returning salmon from reentering their stream of origin (Giannico and Souder 2005, Bottom and others 2005). High velocity outflow also forms scour pools up and downstream of the tide gate, creating a vertical gap between the water surface elevation and the base of the culvert. Culverts that become perched in this manner can form a two way fish passage barrier (Charland 1997), especially when low summer flows are insufficient to fill the scour pools and create the hydraulic gradient needed to open the tide gate (Giannico and Souder 2004, Coos Watershed Association 2006). 
The elevation of the land surface defines the tidal extent and plant community composition (Wetzel and Kitchens 2007). In diked and tide gated systems, tidal flows are intentionally restricted, causing the water table to drop (Giannico and Souder 2005). Terrestrial and invasive plants replace the native emergent wetland species (Portnoy and Giblin 1997). The greater biomass associated with higher surface elevations accelerates the rate of sediment accumulation, further increasing the surface elevation (Cornu and Sadro 2002). The shift from emergent to terrestrial vegetation corresponds to a decline in fish density and species richness (Cornu and Sadro 2002).

\subsubsection{Land Use Practices Associated with Tide Gates}

The land use practices that tide gates are designed to protect typically further degrade estuarine habitats by removing riparian vegetation and habitat complexity, increasing bank instability, and increasing nutrient loading. Riparian vegetation may be removed to improve access to the water way with the result of destabilizing banks and eliminating temperature moderating shade cover. Habitat complexity, including in-channel thermal refugia, may be lost with the removal of riparian vegetation, woody debris and by increasing sedimentation rates (Giannico and Souder 2005). Bank stability is further degraded where livestock have direct access to the water, increasing subsidence, erosion and nutrient loading. Nutrient loading increases algal growth, raising Biological Oxygen Demand, and reducing Dissolved Oxygen levels (Allan 1994). Under these conditions sloughs surpass optimal salmon rearing temperatures of $15^{\circ} \mathrm{C}$, (Richter and Kolmes 2005) and reach lethal thresholds 23-24 $\mathrm{C}$ (Poole and others 2001) in the summer when tide gates open less frequently due to low water levels.

\subsection{Restoration}

\subsubsection{Dike Removal}

From a list of nine criteria: "Guiding Ecological Principles for Salmon Habitat Restoration in the Columbia River Estuary," active restoration of historical salmon habitat via tidal reconnection, is number four. The preceding priorities include: 1) protection of intact habitat, 2) minimizing impact, and 3) passive restoration (Simenstad and Bottom 2009). There are two primary approaches to tidal reconnection: dike removal and tide gate replacement. Reconnection projects are most effective at the larger scales of dike breaching or removal (Frenkel and Morlan 1991). Results from recent dike breaching projects indicate overall success 
in restoring tidal connectivity and habitats, providing fish access to quality forage, and reducing water quality problems (Maris and others 2007). Several comparisons of recently restored and constructed coastal marsh or wetland habitats indicate that fish readily accessed the newly available habitat (Tanner and others 2002, Beamer and LaRock 1998, Gray and others 2002) with densities and species diversity comparable to reference sites (Williams and Zedler 1999).

Despite the similarities in fish diversity and abundance between references and restored sites, most of the restored sites were found to have less available forage, which in a few instances was dominated by chironomids (Gray and others 2002, Miller and Simenstad 1997, Tanner and others 2002). Though short term salmon otolith growth rates were the same between control and impact sites at Gray's Harbor, Washington, salmon in the restored site had lower stomach fullness indices (Miller and Simenstand 1997). Results from a tidal marsh in Virginia indicated that the restored site had a lower accumulation of organic carbon, a primary source of invertebrate forage (Havens and others 2002), perhaps explaining the reduced invertebrate densities in restored sites.

Restoring underlying hydrological functions is critical to overall ecosystem recovery (Williams and Zedler 1999, Gray and others 2002). In restored ecosystems, standing water is less prevalent and previously pooled areas become connected to tidal channels (Tanner and others 2002). Tidal mixing improves water quality and increases nutrient and sediment exchange, leading to the rapid response and high productivity of the restored systems in the studies cited above. The short term response to tidal mixing may be either hindered or enhanced by less frequent high flows depending on how well the underlying hydrology was restored (Gray and others 2002).

Cautions for large scale restoration include assessing the degree of subsidence, sediment budget, and biogeochemical processes. If tidal range and forecasts of sea level rise are not carefully assessed, former marshes may become lakes, and the distribution of tidal wetlands may overtake other habitat types upstream of their historical range (Boumans and others 2002). Using fill material to increase surface elevation may compensate for the effects of subsidence until natural sediment dynamics are restored (Cornu and Sadro 2002). Hydraulic geometry may be used to predict channel evolution in restored sites, which may degrade or aggrade depending on the sediment dynamics at the site (Williams and others 2002). Newly restored sites without proper protection may expose the shoreline and other areas to increased storm erosion and areas 
without vegetation cover to colonization by invasive species (Turner and Lewis 1997). Prior to restoring the tide, the current biogeochemical condition should be assessed to prevent the distribution of toxins that may have been produced by biogeochemical reactions in the soil while exposed to the atomosphere (Portnoy 1999). The optimal amount of tidal flushing and depth should also be determined to ensure a long term stable geochemical environment (Beck and others 2001).

\subsubsection{Tide gate replacement}

Where large scale dike removal isn't feasible, tide gate replacement is a possible alternative for restoring minimal ecosystem function, although the smaller the tidal inflow, the more restricted the extent of its reach and the smaller the extent of restored habitat (Beamer and LaRock 1998). Several new tide gate models are designed to improve fish passage, habitat and water quality conditions while continuing to manage flow regimes to protect agriculture and other infrastructure (Giannico and Souder 2005). Though tide gate replacement with "fish friendlier" models is one of the few restoration options available that maintains existing infrastructure, whether these new gates live up to their claims has been poorly studied (Coos Bay Association 2006, Tonnes 2007, Giannico and Souder 2005). Preliminary results indicate gates that allow regular tidal inflow, in addition to outflow, improve both salmon passage and water quality (Tanner and others 2002, Barendregt and others 2006), whereas tide gates that allow more complete upland drainage without additional recharge can worsen conditions (Coos Watershed Association 2006).

Newer tide gates include one or more of the following features: lighter materials, sidehinged doors, 'fish orifices,' and self-regulating mechanisms (Giannico and Souder 2005). These gates are designed to open with a lower pressure differential, increasing the frequency and duration of openings, while also reducing water velocity and turbulence, providing increased passage potential and a gradual transition between upsteam and downstream habitats relative to conventional tide gate designs (Giannico and Souder 2005). The weight of the material and the direction of the hinging factors into the frequency and duration of openings, while the fish orifice and self-regulating attributes allow for inflow and fish passage during flood tides. The fish orifice is a smaller door in the larger tide gate that may be operated manually to remain open or closed during the incoming tide or may be self-regulated and remain open a portion or all of the incoming tide. Self-Regulating Tidegates (SRT) stay partially open except during particularly 
high tides when a float operated lever forces the gate closed to prevent upstream flooding (Giannico and Souder 2005).

The features that facilitate bidirectional flow generally increase fish passage and improve upstream water quality and connectivity. Tidal inflow allows for thermal and nutrient mixing and sediment exchange (Maris and others 2007). Higher upstream surface water elevation can raise the water table and restore wetland plant species (Frenkel and Morlan 1991). In the Netherlands, reopening gates to tidal exchange ameliorated toxic algae blooms and also reduced the extent of stagnating water, improving water quality (Maris and others 2007). On Fisher's Slough, on the Skagit River in Washington, water temperatures consistently declined with the introduction of cooler water from flood tides through a Self-Regulating Tidegate (Tonkin 2009).

Side hinged tide gates, if they are not managed to allow inflow, may in fact exacerbate poor water quality conditions. Because they open with only a slight pressure differential, they allow greater drainage, causing water surface elevation to drop to the level of the low tide with each opening (Coos Watershed Association 2006). During periods of low flow, the slough may not recharge sufficiently to build up the pressure differential required to open the gate during the next low tide, increasing the temperature of the slack water upstream (Coos Watershed Association 2006). On Kunz Slough in Coos Bay, a tide gate replaced with a side hinged model was open less than $25 \%$ of the time in winter and less than $12 \%$ of the time in spring and still less in summer when it only opened every other low tide (Coos Watershed Association 2006). Tide gate replacement projects should proceed with caution and carefully consider strategies to manage the new gate to optimize restoration of underlying functions and processes.

\subsection{BACI Study Design and Analytical Methods}

\subsubsection{Before-After, Control-Impact}

A Before-After, Control-Impact (BACI) is often selected as an optimal study design for its ability to detect an impact to an ecosystem (Green 1979, Smith and others 1992). Data are sampled concurrently at both the control and the impact sites with the assumption that both sites will respond similarly to system-wide changes. In Figure 7 B, mean temperatures at the impact site decreased significantly while they increased only slightly at the control site. Given that the change occurred only at the impact site and increased the temperature difference between sites, the change may be attributed to the impact if consistent with other evidence. In Figure 7 A 
however, temperatures decreased at both sites and the difference in temperature between the control and the impact site is similar before and after the impact. Because both sites were affected similarly and the difference between them was not significantly altered, the changes cannot be attributed to the impact (Smith and others 1992, Stewart-Oaten and others 1986, Manly 2008).

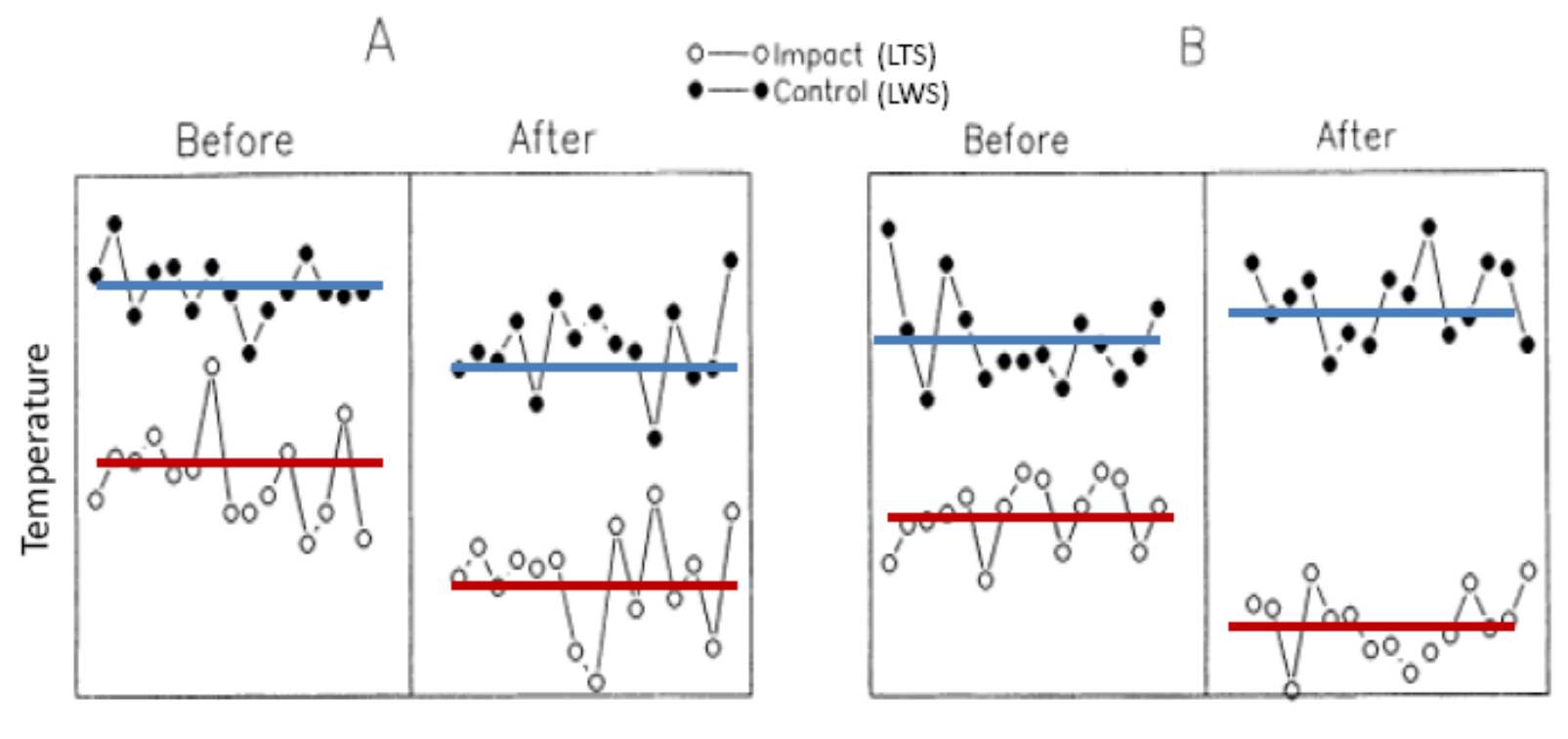

Time

Figure 7. BACI detects a change to an ecosystem by testing the change in the difference between the control and impact sites, before and after an impact, for significance. In figure $A$, the mean temperature decreased at both the control and the impact sites after the impact. Because the temperature change affected both sites similarly, and because the difference in mean temperature was similar before and after the impact, the temperature change cannot be attributed to the impact. Figure B illustrates a scenario where the difference in mean temperature between sites increased significantly after the impact. Because the only significant temperature change occurred at the impact site, with additional supporting evidence, the change may be attributed to the impact. From Steward-Oaten (1886).

In 1979, Green developed the predecessor to the BACI design, which required a single sample from the control and impact sites both before and after the impact. The low sampling frequency of this design heightened the risk of detecting a response when there was none. To address this problem, Stewart-Oaten and others (1986) introduced paired or concurrent sampling, at both the control and impact sites with increased frequency before and after the impact, assuming the timing of the impact is known. Underwood (1992) argues for higher frequency sampling temporally and spatially and additional reference sites, indicating that a single reference is inadequate due to variability between similar sites. To remedy this flaw, Underwood 
amends the BACI design by including multiple control sites, which can be used to determine a wider range of natural variability within the system, producing greater confidence in the results.

\subsubsection{Randomized Intervention Analysis (RIA)}

Using a variation of a Monte Carlo method (described in the methods), RIA was designed to detect a change after an impact in BACI study designs using one control and one impact site (Carpenter and others 1989). Because RIA tests for a significant change in the difference between the two sites, before and after the impact, it is not biased by changes in ambient conditions that affect the control and impact sites equally and can therefore be used to detect a change after an impact. This method is particularly useful with time series data that are not normally distributed and where replication of the impact is not possible. RIA does not prove that an impact caused a change, only that a change occurred (Carpenter and others 1989).

The assumptions of RIA are less strict than parametric tests and less likely to be swayed by extreme values (Smith and others 1992). However, Stewart-Oaten (1992) caution that RIA is no panacea to the difficulties associated with parametric tests. Carpenter and others (1989) are careful to explain potential violations: 1) data values must be paired in time, 2) serial autocorrelation, and 3) discrepancies in response between sites, discussed below.

1) Samples from the control and impact sites must be taken as close in time as possible to prevent the introduction of unwanted variation. Collecting samples paired in time attempts to address the issue of additivity, identified by Stewart-Oaten, and others (1992). Additivity implies that in the absence of a disturbance, the difference between the data from the control and impact sites is the same for all dates. Effects of seasonal and random natural variation may result in non-additivity and unequal variance (Stewart-Oaten, and others, 1992), violating the assumptions of the test, and therefore must be accounted for or avoided.

2) Carpenter and others (1989) and Stewart-Oaten, and others (1992) conflict on the point of independence. Carpenter and others state valid results may still be produced by a lack of independence among sequential observations, although autocorrelation may result in an underestimate of the true p-value. They remedy this tendency by setting the significance level at $\mathrm{p}<0.01$ instead of 0.05. Stewart-Oaten and others (1992) argue that if the correlation is weak, a significance level of 0.01 is too conservative and that in the case of strong auto correlation, test results are not valid regardless. Nevertheless, Smith and others (1992) indicate that the RIA 
process of creating a frequency distribution from random permutations of the data addresses assumptions of normality and serial autocorrelation.

3) Carpenter and others (1989) and Stewart-Oaten and others (1992) also disagree on the importance of equal variance in the difference between the control and impact sites, before and after the manipulation. Carpenter and others state that RIA is not affected by heterogeneous variances, but caution against falsely detecting a change in the case that each site responds differently to the same conditions. They recommend interpreting RIA results in conjunction with response vs. time graphs to distinguish between trends caused by the manipulation and natural variation. Stewart-Oaten and others, highlight equal variance as a critical assumption for randomization tests. Equal variance among the before and after data indicates the effect of the manipulation is complete and removes other variation, distinguishing the effect of the manipulation from natural random variation (Stewart-Oaten and others. 1992). However, these conditions are more difficult to meet and are subsequently applicable to fewer data sets. Additional control sites partially address the concern over equal variance by improving the understanding of natural variability between sites and thereby reduce the risk of detecting a change when none occurred (Underwood 1992).

Disadvantage of RIA includes the lack of comparability with the results of other significance tests and the variability of the results with each successive permutation. Because RIA creates a new distribution specific to the data each time it is run, it is not standardized like other distribution curves and the p-values resulting from repeat iterations of the same test vary slightly. This nonparametric tool is useful however, when data fail to meet the assumptions of parametric analytical methods. 


\subsection{Study Area}

US Fish and Wildlife (USFWS) staff collected data from Welch Island on the Lewis and Clark National Wildlife Refuge and from Tenasillahe Island, part of the Julia Butler Hansen National Wildlife Refuge (JBH NWR). Both islands are on the main stem of the Columbia, Welch at river kilometer 55 and Tenasillahe at river kilometer 56 at a latitude of $46.22^{\circ} \mathrm{N}$ and longitude of $123.45^{\circ} \mathrm{W}$ near the town of Cathlamet, Washington. Average annual precipitation is $201.5 \mathrm{~cm}$ (USACE 2007), winter air temperatures average $6^{\circ} \mathrm{C}$ and summer temperatures average $16^{\circ} \mathrm{C}$ (Accuweather 2009). Welch Island is just to the north of Tenasillahe Island (see Figure 8) and both are beyond the salinity gradient, but are subject to tidal fluctuations of up to three meters during the study period, from March through June. Following is a description of the control and impact sites on Welch and Tenasillahe Islands respectively, which is also summarized in Table 1.

Table 1. Comparison of size, slough length, tidal range, flood regime, recharge, fish species, vegetation cover, infrastructure, grazing, and baseline water temperature before the impact late in 2007, between Welch Island, the control site, and Tenasillahe Island, the impact site,

\begin{tabular}{|l|l|l|}
\hline Parameter & Welch Island (Control) & Tenasillahe Island (Impact) \\
\hline Island Size & 429 hectares & 809 hectares \\
\hline Slough Length & $\sim 2.0 \mathrm{~km}$ & $\sim 3.5 \mathrm{~km}$ \\
\hline Tidal Range & $>3.0 \mathrm{~m}$ & $\sim 1.5 \mathrm{~m}$ \\
\hline Flood Regime & Seasonally & Rarely \\
\hline Recharge & Inflow & Seepage, ground water, precipitation \\
\hline Fish Species & Native species including salmonids & Warm water invasive species \\
\hline Vegetation & Shrub-scrub: native species & Upland deciduous: invasive species \\
\hline Infrastructure & None & 3 tide gates, dikes around perimeter \\
\hline Grazing & None & Cattle, ESA listed White-tailed deer \\
\hline $\begin{array}{l}\text { Water Temperature } \\
\text { 2006-2007 }\end{array}$ & $9.5-19.5^{\circ} \mathrm{C}$ & $12.0-20.2^{\circ} \mathrm{C}$ \\
\hline
\end{tabular}




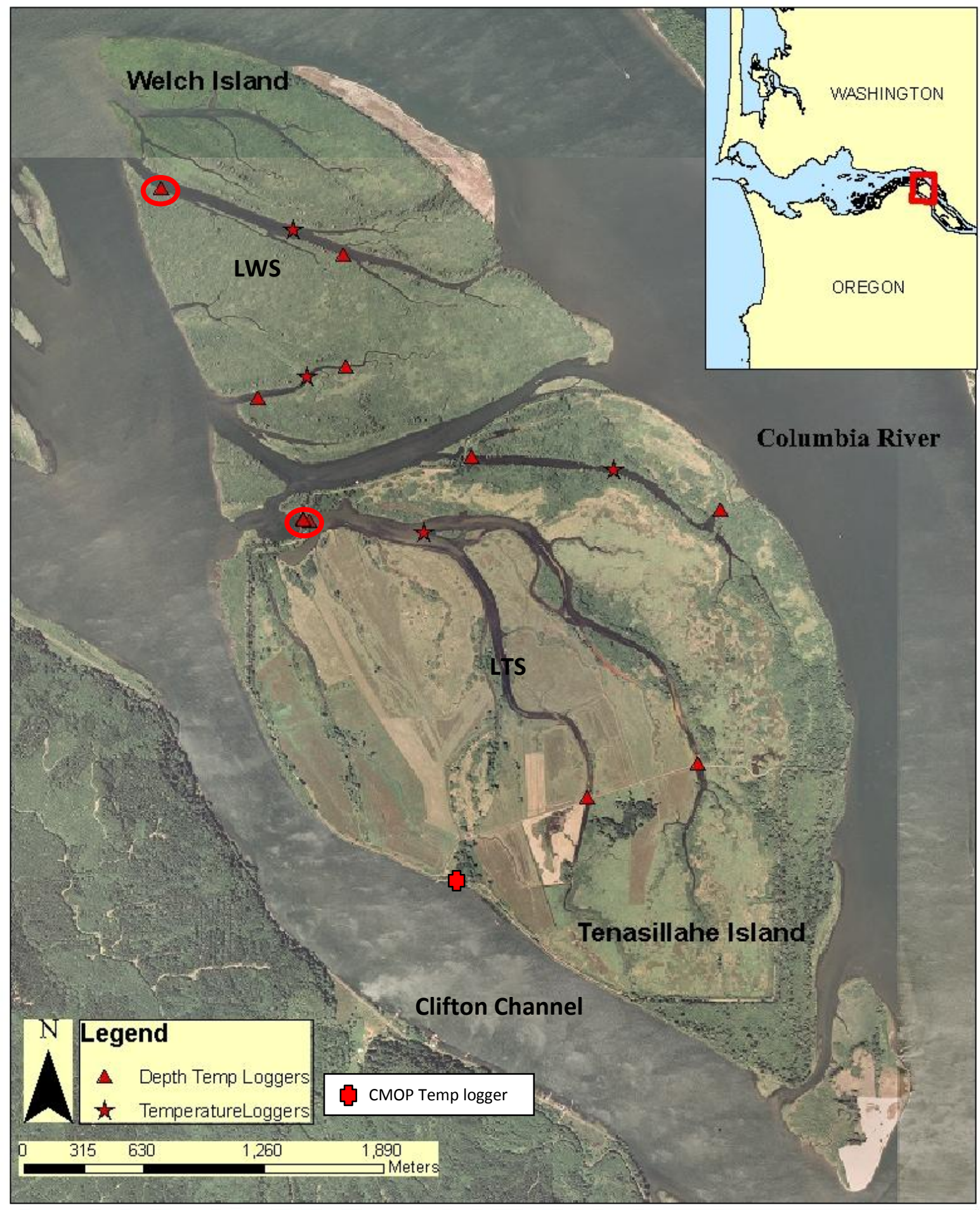

Figure 8. The study site is located in the Lower Columbia River Estuary, inset upper right. The control site, LWS, is located on Welch Island to the north and downstream of the impact site, LTS, on Tenasillahe Island. Data used for this study were collected at the circled temperature loggers and by the CMOP temp logger. 


\subsection{Welch Island}

The tidal marsh habitat on the approximately 430 hectare Welch Island is minimally impacted with no evidence of human development. Without levees and tide gates, Welch Island floods seasonally during periods of high flow. The dominant slough on the island, Large Welch Slough (LWS) is approximately $2 \mathrm{~km}$ long and gradually widens as it approaches the mouth. The mouth is near the northwest tip of the island and flows into Clifton Channel shortly before the confluence with the Columbia River (Figure 9). Of the fish sampled in Welch, over 90\% were native, consisting primarily of salmonids after the ubiquitous Three-spined stickleback (Gasterostreus aculeatus). Vegetation on Welch Island is characterized as "shrub scrub wetland" and consists of native grasses, shrubs and small trees (Johnson and others 2003).

Due to the lack of tide gates or other obstruction, LWS experiences the full range of tidal fluctuations. In the graphical depiction of temperature and tide height in Figure 10, chosen as representative of dynamics in LWS for the four years of data collection, temperature is relatively consistent during the higher high tides of the neap tide cycle through $4 / 8$ when tidal flushing is most thorough. As low and high tides decrease in height (4/9 to 4/14), the temperature spikes. These spikes may be caused by the combined effects of reduced tidal circulation and the greater influence of solar radiation on the shallower water in the slough. The temperatures stabilize with the return of more even tides (4/14 to 4/19). The high variety of habitat structure, and variability of temperature and depth in LWS make it a generally ideal rearing site for juvenile salmon.

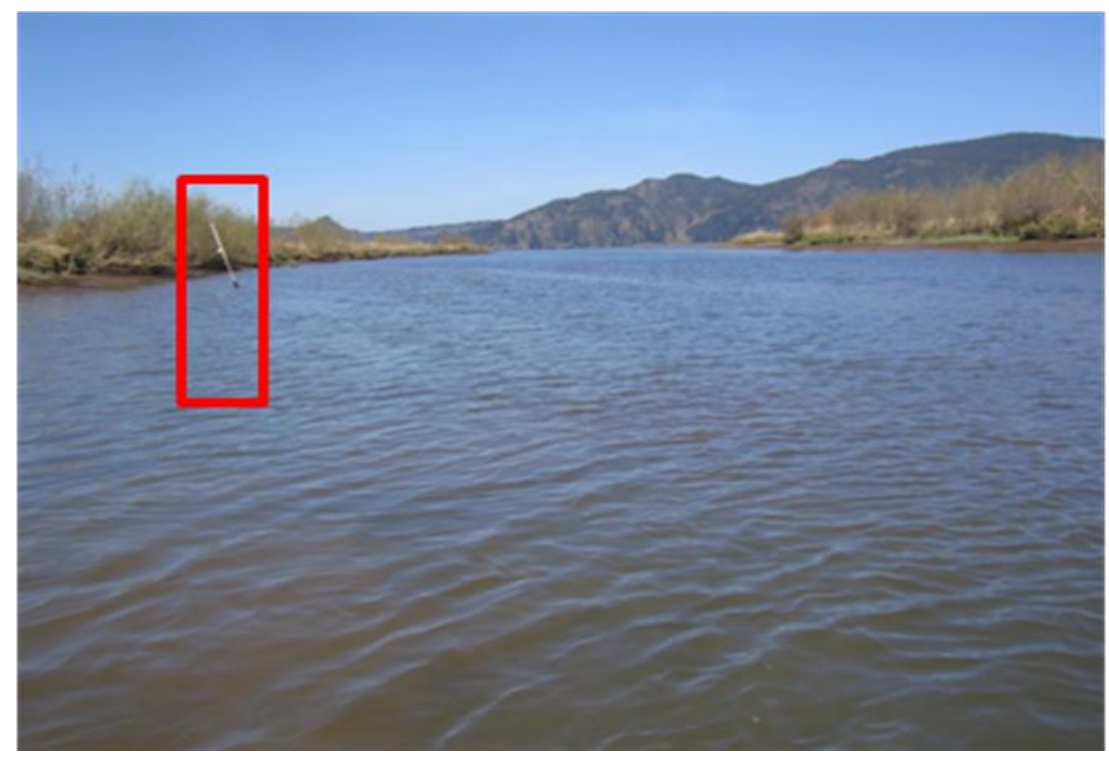

Figure 9. The mouth of Large Welch Slough. The temperature logger, placed in PVC pipe in the box on the left, is $300 \mathrm{~m}$ from the mouth of the slough. 


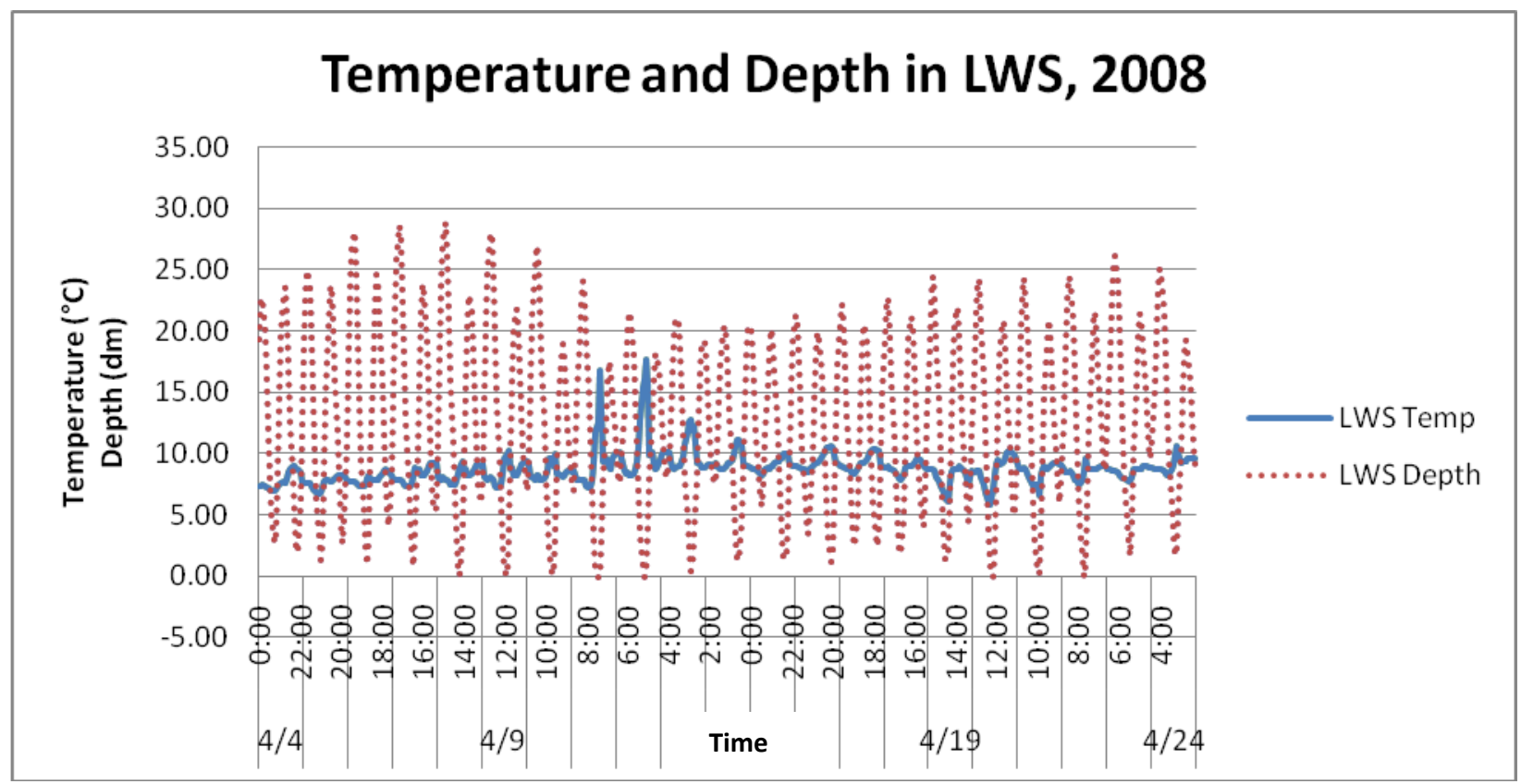

Figure 10. Hourly water surface elevation (WSE) in decimeters (dashed line) and water temperature in ${ }^{\circ} \mathrm{C}$ (solid line) in LWS. Data collected from April $4^{\text {th }}$ to June $13^{\text {th }}, 2008$.

\subsection{Tenasillahe Island}

By comparison, all habitats on the 809 hectare Tenasillahe Island have been heavily impacted with six miles of flood control levees around the island perimeter. Large Tenasillahe Slough (LTS), the largest slough on the island, has two primary forks, each approximately 3.5 $\mathrm{km}$ long. The slough is blocked at the mouth by three adjoining tide gates placed into the levee. Due to high velocity flows when the gates are open, scour pools have formed both up and downstream of the culverts. Water drains from the slough through three culverts $(2.1 \mathrm{~m}$ diameter) to the tide gates, through another length of culvert, and into a small bay before flowing into Clifton Channel and the Columbia River. The downstream end of the tide gates is depicted in Figure 11.

Due to the levees and the tide gates, the island seldom floods and much of the historical marsh habitat has disappeared. The tide gates manage water exchange, causing upstream waters to back up when closed and allowing outflow when open. Primary sources of recharge into the slough include seepage through the dike, precipitation, and ground water (Figure 12). Flood prevention, combined with moderate sources of recharge, has caused the water table to drop, as indicated by the replacement of wetland with terrestrial plant species. More than $30 \%$ of the fish in LTS are non-native warm water species. Island vegetation is characterized as upland 
deciduous forest (Johnson and others 2003) including Red Alder (Alnus rubra) and non-native species including yellow flag iris (Iris pseudacorus), Himalayan blackberry (Rubus armeniacus), and reed canary grass (Phalarus arundinacea).

The flood control levees were constructed in the 1920's to provide pasture for cattle. Currently, Tenasillahe Island is managed for three herds of Columbian White-Tailed Deer listed as threatened under the Endangred Species Act (ESA) and 340 head of cattle that are barged to the island and grazed there from March through July (David, personal communication). The deer remain on the island for the majority of the year and graze throughout. The cattle graze in eight different pastures on 138 hectares of the northern end of Tenasillahe island, each pasture with a point of access to a slough. Nutrient loading from cow manure is evident in the high algal productivity in the sloughs. The lack of inflow, land use practices, and solar radiation dominate temperature dynamics upstream of the tide gate in LTS (Figure 3).

Figure 13 illustrates temperature and depth dynamics both up and downstream of the tide gates. Upstream is most directly influenced by the operation of the tide gates and as such is the impact site of primary interest. Downstream is an impact site of secondary interest as it is moderately influenced by tide gate operation but is largely influenced by the tidal dynamics of the larger estuary. Figure 13 provides an approximation of tide gate openings, indicated by the intersection of the water surface elevation up and downstream. Upstream temperatures drop slightly with tide gate openings at the low tide, but remain consistently high. The higher upstream temperatures cause the downstream temperature spikes as the warmer water is released through the open gates. Values are an approximation given that water depths have not been referenced to a benchmark.

\subsection{Tide Gate Replacment, "Restoration" or "Impact"}

In August 2007, the top-hinged, cast-iron tide gates (Figure 14a) were replaced with sidehinged aluminum gates (Figure 14b) designed to open more frequently and for greater duration as a result of the reduced hydraulic pressure required to open them. In this study, tide gate replacement is synonymous with "restoration" and is the "impact" in the BACI study design. The new gates have a manually operated fish orifice. Left open, these orifices would allow inflow to the slough during high tide and increase fish passage potential and water circulation, however they were closed during the data collection periods. Two culverts, located 
approximately $3 \mathrm{~km}$ upstream of the fork on each branch of the slough were replaced by bridges in 2007 to enhance connectivity between slough reaches (Poirier, personal communication).

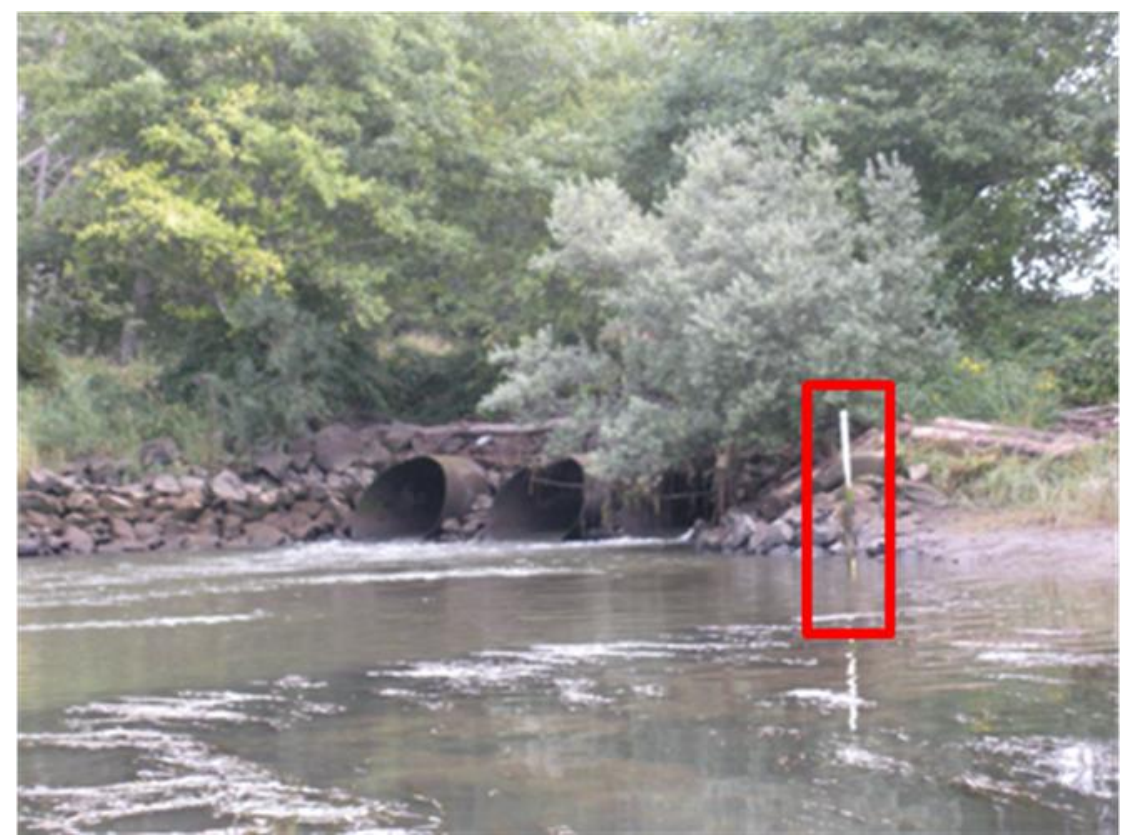

Figure 11. Downstream end of the culverts in the dike on LTS. The data logger is in the PVC pipe in the box on the right. The upstream portion of the slough is behind the trees. Photo taken during ebb tide. Flow at mouth of culverts indicates gates are open.

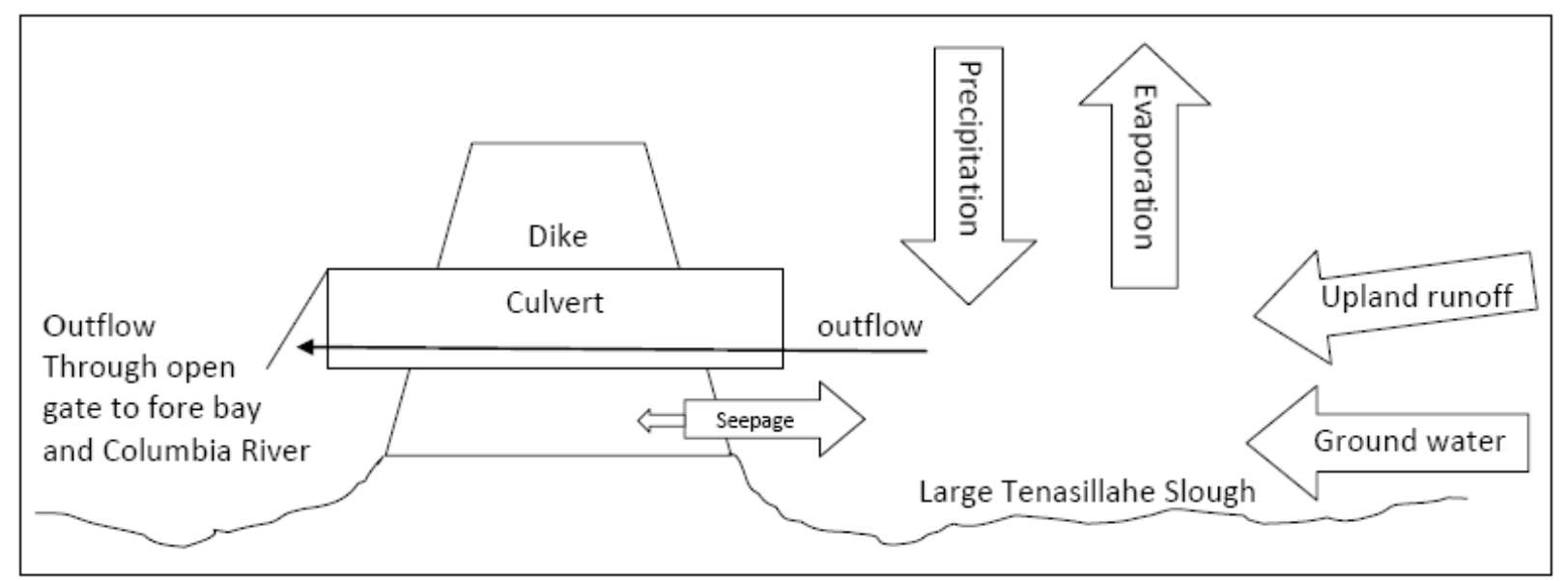

Figure 12. Whereas an unobstructed slough like LWS recharges primarily via tidal inflow, recharge to a gated slough like LTS, occurs via seepage through the dike, precipitation, runoff, and ground water. Water leaves the slough as it drains through the culvert at low tide and through evaporation. If outflow is greater than the rate of recharge, water levels in the slough decrease. 


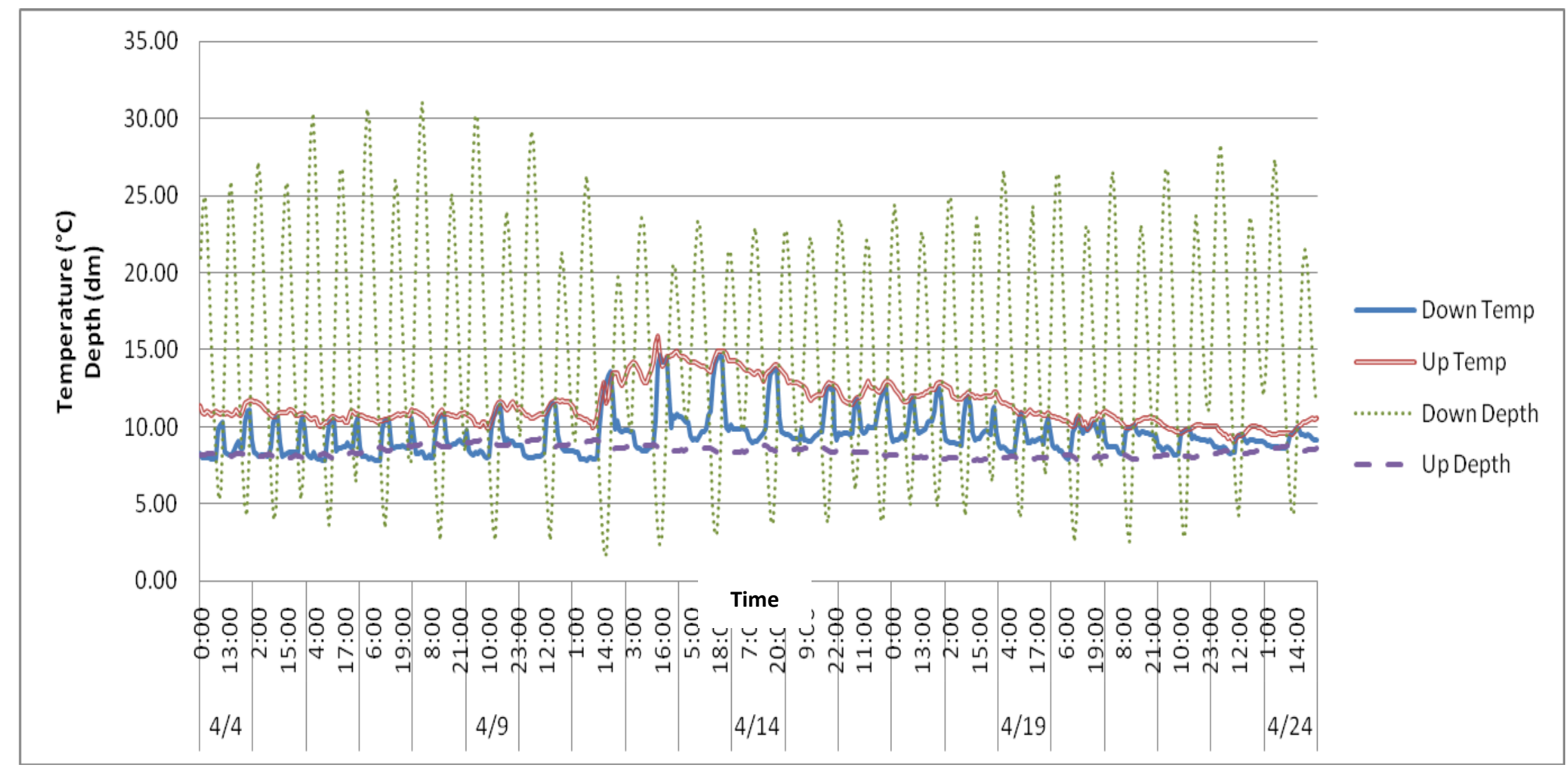

Figure 13. Hourly water surface elevation (WSE) in decimeters (dotted and dashed lines) and water temperature in ${ }^{\circ} \mathrm{C}$ (solid lines) in LTS. Data collected from April $4^{\text {th }}$ to June $13^{\text {th }}$ in 2008. 

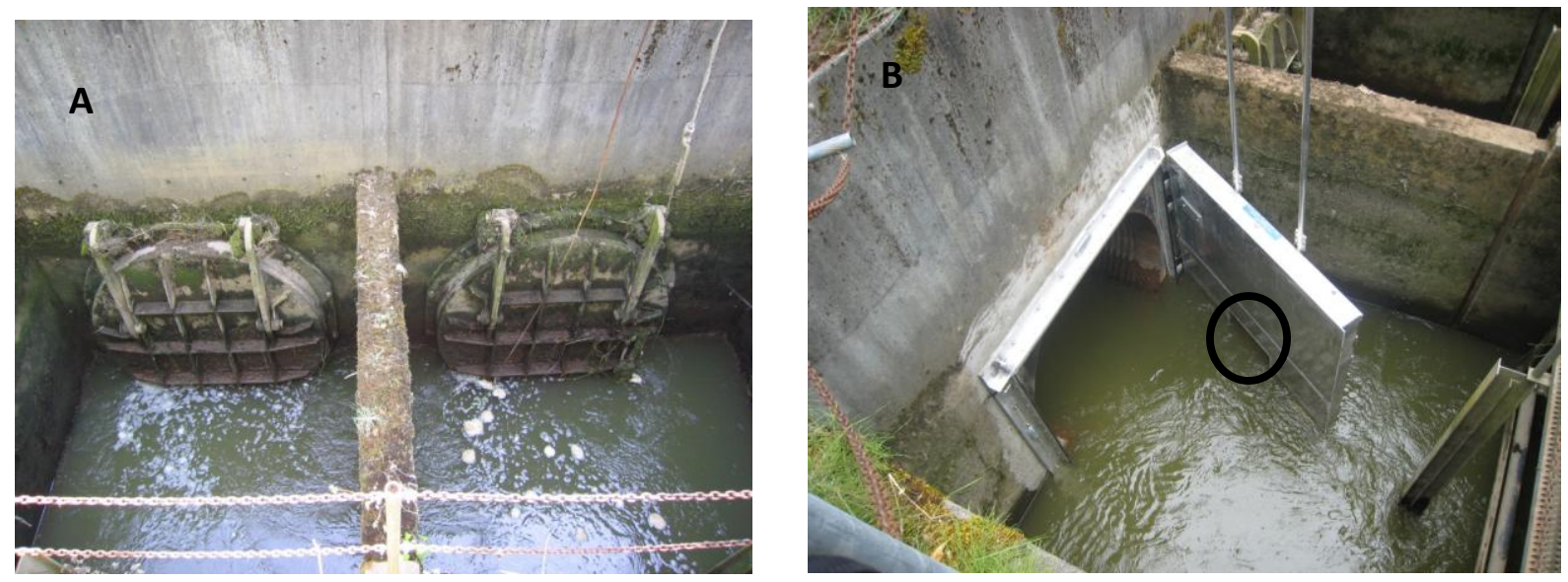

Figure 14. Top-hinged, cast-iron tide gates (A) on Tensillahe were replaced after the data collection period in 2007 with side-hinged aluminum gates $(B)$ with a manually operated fish orifice (circled) designed to open with lower hydraulic head increasing the frequency, duration and width of openings. 


\subsection{Methods}

\subsection{Site Selection}

Due to the tide gate replacement in 2007, LTS is the impact site by default. Welch Island was chosen as a reference because of its minimally impacted condition and its proximity to Tenasillahe Island, such that both are subject to the same ambient conditions while being far enough apart to limit the effects of spatial autocorrelation. LWS was chosen for its comparable size and as a prototype for LTS prior to disturbance. A location in LWS $300 \mathrm{~m}$ upstream of the mouth was selected as a site for the reference logger. The logger was placed where it would be continually submerged on the south side of the channel. The sites for the loggers in the impact site were selected to capture the greatest range of temperature variability upstream and downstream, but were placed 1-3 $\mathrm{m}$ to the side of the tide gates to avoid the high velocity flows during operation.

\subsection{Data Collection and Preparation}

Onset hobo water level loggers recorded hourly water temperature and depth from late March through mid June for all years of the study, 2006 to 2009. These dates were chosen to coincide with peak fish migrations. Each logger was individually calibrated by the manufacturer, Onset. Using Hobo software, a coupler and a USB optic base station, loggers are connected to the computer and programmed for a start time and collection frequency (Onset 2008). Prior to deployment, staff anchored loggers in a perforated PVC pipe, installed approximately $15-20 \mathrm{~cm}$ above the surface of the substrate (Johnson and others 2007). A reference logger on Tenasillahe Island recorded air temperature and barometric pressure to calibrate the atmospheric pressure data collected by the submerged loggers each year.

The pressure data collected can be converted into site specific depths. Because the logger elevation was not referenced to a benchmark, these depths cannot be compared between sites, but were used for correlation analysis with temperature data collected at the same site. At the end of the data collection period, loggers were removed and data downloaded to a computer in the same manner used to set the launch time. For the depth and temperature correlation analysis, I used the raw hourly data to examine daily fluctuations. For all other analyses, I used the daily maximum temperature and calculated the weekly average to get a Seven Day Average Daily Maximum (7-DADM) to minimize the influence of short term temperature extremes and reduce 
the propensity of serial autocorrelation. This method is used by the Environmental Protection Agency to set temperature standards for fish habitat requirements (OR DEQ 2008). To reduce seasonal variability, I used data from the same dates for all years: April $4^{\text {th }}$ to June $13^{\text {th }}$.

Data for other environmental variables came from the websites of different agencies. Water temperature data $\left({ }^{\circ} \mathrm{C}\right.$ ) for Clifton Channel (Figure 8) came from from the temperature gage station located on the US Fish and Wildlife dock on the west side of Tenasillahe Island operated by the Center for Coastal Margin Observation and Prediction website: http://www.ccalmr.orgi.edu/CORIE/data/publicarch/tnslh/, and were converted to 7-DADM to be consistent with other temperature data. Daily discharge data, measured in Cubic Feet per Second (CFS), were collected by USGS at the station located near Oak Point, Oregon, approximately $30 \mathrm{~km}$ upstream of the study site (http://waterdata.usgs.gov/nwis/dv?referred_ module $=$ sw\&siteno $=14246900$ ). Refuge staff collected and recorded daily precipitation data $(\mathrm{mm})$ on the JBH NWR mainland.

\subsection{Study Design: Before-After, Control-Impact}

The temperature data from the mouth of LWS served as the control site. Upstream of the tide gate is the impact site of primary interest, due to the greater influence of the tide gates in preventing tidal circulation and due to the accentuated effects of grazing. Downstream of the tide gates is an impact site of secondary interest, given that water temperature is influenced by tide gate operation, however not as directly as upstream due to the greater influence of tidal dynamics in the adjacent Clifton Channel. Data were collected two years before and two years after the tide gates were replaced (the impact) in late 2007.

Table 2. BACI study design including years of data collection before and after the impact and the control and impact sites.

\begin{tabular}{|l|l|l|l|}
\hline Before & After & Control & Impact (Tide gate reaplacement) \\
\hline 2006-2007 & $2008-2009$ & LWS & $\begin{array}{l}\text { LTS Up (primary) } \\
\text { LTS Down (secondary) }\end{array}$ \\
\hline
\end{tabular}

\subsection{Data Analysis}

Table 3 indicates the methods used to address each of the study questions. The two primary methods of analysis employed were Monte Carlo and a modified version of Monte Carlo used in RIA. RIA effectively addressed the primary study objective of whether or not tide gate 
replacement affects slough water temperature, designed specifically for BACI studies to detect a change after an impact, it is also amenable to time series data that are not normally distributed. RIA is less influenced by natural variability than a pure Monte Carlo method, because it uses the difference in means between the before and after data for two sites. Monte Carlo tested for significant differences in daily range before and after tide gate replacement and for differences in temperature between sites and between years. Because Monte Carlo can be used to compare any two sets of data, it provided more detailed information about inter-annual and site to site variation. Spearman Rank Correlation analysis provided information on the relationship between hourly temperature and depth at the study sites and the degree of influence of other variables on water temperature.

Table 3. Research questions and analytical methods used to address them.

\begin{tabular}{|l|l|}
\hline $\begin{array}{l}\text { Question } \\
\text { water temperature? }\end{array}$ & Analytical Methods \\
\hline $\begin{array}{l}\text { 1b) Did tide gate replacement affect salmon } \\
\text { rearing habitat in terms of water } \\
\text { temperature? }\end{array}$ & $\begin{array}{l}\text { • Daily temperature range (RIA) } \\
\text { — Temperature Exceedances }\end{array}$ \\
\hline $\begin{array}{l}\text { 2) What was the natural variability between } \\
\text { sites and between years? }\end{array}$ & • Temperature-Depth Correlation (Spearman) \\
\hline 3) What other variables affect slough water \\
\begin{tabular}{l} 
temperature? \\
\hline
\end{tabular}
\end{tabular}

\subsubsection{Monte Carlo Method}

The Monte Carlo method simulated replicates by randomly reassigning "Before" or "After" labels to each of the data values regardless of when it was collected and calculating the difference. The process of random assignment was repeated 1000 times and the difference values are used to create a frequency distribution. The proportion of values that met or exceeded the actual difference between the means of the before and after data was the probability, or test statistic (Carpenter and others 1989). I used a program developed by Christian Parker and Yangdong Pan using the open source statistical software, R. Input data was saved as a Comma Separated Values (CSV) file with data in two columns, the first labeled "y" with followed by the data values and the second column labeled "group" with two different groups. I used this 
method to test for a difference between two different years or two different locations and entered the appropriate value accordingly.

\subsubsection{Randomized Intervention Analysis}

Loggers collected temperature data concurrently in the control (LWS) and impact (LTS) sites so that they were paired in time before and after the impact (Carpenter and others 1989). Using a Monte Carlo method, the absolute value of the difference between the means for each site was calculated for before and after the impact to derive the test statistic, which was estimated by 1000 random permutations of the data. The null hypothesis indicated that all possible permutations of the data had an equal probability of being observed. The proportion of values that met or exceeded the test statistic was the p-value, or probability that a given value would be derived by random chance. Because of the variability in the p-values resulting from each permutation of the test, Carpenter and others (1989) recommend a conservative significance level of 0.01 .

I received the public domain RIAPUB program from Sue Eggert of the US Forest Service in Grand Rapids, Minnesota. Input data is saved as a text file with all data for a give site both before and after, with unlabeled column headings. The first column is the number "1" or " 2 ", the second is the two digit year, the third is the Julian day and the fourth column is the data value. Data must be left justified. The prompt in the RIAPUB program asks for the file names, the total number of samples taken at each site for a maximum of 300 , the maximum number of days between samples, and date of impact. The program computes pre and post manipulation means, the difference between pre and post means, their pooled standard deviation, lags that address potential serial auto correlations in the data, and the p-value based on 1,000 permutations (Carpenter and others 1989). The program is MS-DOS and sends the results directly to the printer terminal. In modern computers this is a USB port, and a conversion program must be used send the results to the correct location. I downloaded a free conversion program from http://www.dos2usb.com/.

\subsubsection{Spearman Rank Correlation Analysis}

I used another program developed by Christian Parker using the R software to create a correlation matrix, using the non-parametric, Spearman rank method. The matrix produces correlation values for water temperature up and downstream of the tide gates, in LWS, in Clifton 
Channel, air temperature, precipitation and Columbia River discharge. Data were also saved in a CSV file with column labels for each category followed by the data values.

\subsubsection{Fish Related Analyses}

Given that fish are less concerned with mean temperatures than extremes, I examined changes in daily temperature range, the relationship between temperature and depth, and calculated the number of days temperature thresholds exceeded EPA standards. Daily range was calculated by subtracting the daily minimum from the daily maximum and I used RIA to test for significant changes in these values after tide gate replacement. Spearman rank correlation coefficients were calculated for hourly temperature and depth data for all sites. Temperature Exceedances were calculated based on the Environmental Protection Agency (EPA) standard of a 7-DADM of $18^{\circ} \mathrm{C}$ for rearing habitat temperature in middle and lower reaches. 


\subsection{Results}

\subsection{Effect of Tide Gate Replacement on Water Temperature}

The results of the analysis indicate that tide gate replacement had no significant effect on mean water temperature. Mean water temperature decreased in all the study sites by 0.98 to $1.22^{\circ} \mathrm{C}$ after replacement (Figure 15, Table 4). Minimum temperatures decreased in all sites, however by 2.79 and $2.91{ }^{\circ} \mathrm{C}$ up and downstream of the gates respectively and by only $0.67^{\circ} \mathrm{C}$ in LWS. Maximum temperatures generally decreased, with the exception of upstream where the maximum temperature increased. Figure 16, illustrating the temperature range for each site by year, indicates that the increase in maximum temperature upstream occurred in 2008 only.

RIA results were not significant for the comparison of the upstream-LWS comparison, but were significant for the downstream-LWS comparison (Table 5). Upstream and LWS experienced nearly the same temperature change of $0.98^{\circ} \mathrm{C}$ and $0.99^{\circ} \mathrm{C}$ respectively (Table 2). The non-significant RIA results for this comparison indicate that no change in the temperature difference occurred due to replacement. Mean downstream temperatures decreased by $1.22^{\circ} \mathrm{C}$ compared to the $0.99^{\circ} \mathrm{C}$ decrease in LWS. The change in the difference of $0.23^{\circ} \mathrm{C}$ between these two sites tested as significant via RIA.

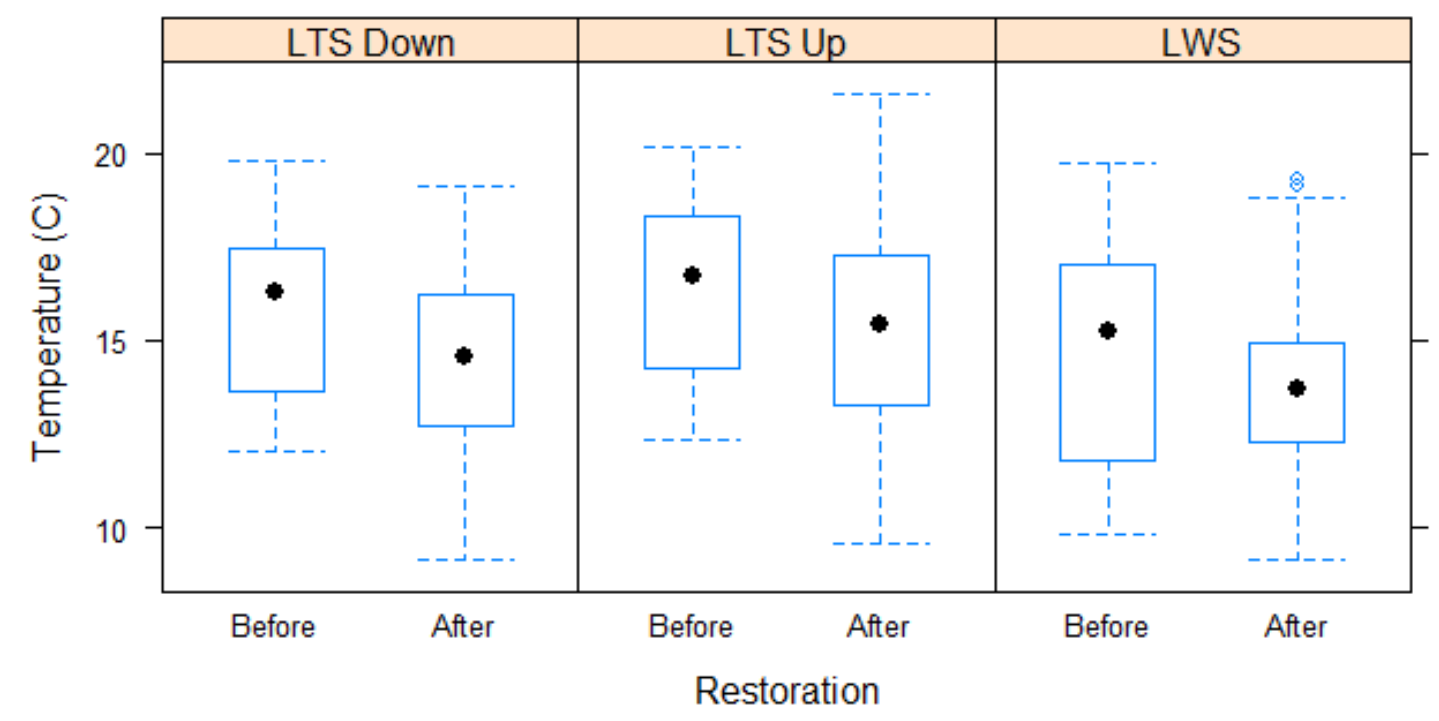

Figure 15. Boxplots of 7-DADM temperatures $\left({ }^{\circ} \mathrm{C}\right)$ before and after tide gate replacement (restoration) for downstream of the tide gates (secondary impact site), upstream of the tide gates (primary impact site), andLWS (control). 
Table 4. Summary statistics for 7-DADM temperatures $\left({ }^{\circ} \mathrm{C}\right)$ before and after tide gate replacement and the difference between them for the three study sites: downstream, upstream and LWS.

\begin{tabular}{|l|r|r|r|r|r|r|r|r|r|}
\hline & \multicolumn{3}{|c|}{ Downstream } & \multicolumn{3}{c|}{ Upstream } & \multicolumn{3}{c|}{ LWS (control) } \\
\hline Summary & \multicolumn{1}{|c|}{ Before } & \multicolumn{1}{|c|}{ After } & Difference & Before & \multicolumn{1}{c|}{ After } & Difference & Before & \multicolumn{1}{|c|}{ ffter } & Difference \\
\hline Minimum & 12.04 & 9.13 & -2.91 & 12.36 & 9.57 & -2.79 & 9.83 & 9.16 & -0.67 \\
Median & 16.31 & 14.57 & -1.74 & 16.72 & 15.42 & -1.30 & 15.24 & 13.71 & -1.53 \\
Mean & 15.84 & 14.62 & -1.22 & 16.39 & 15.41 & -0.98 & 14.66 & 13.67 & -0.99 \\
Max & 19.81 & 19.13 & -0.68 & 20.18 & 21.58 & 1.40 & 19.73 & 19.30 & -0.43 \\
IQR & 5.42 & 3.47 & -1.95 & 4.09 & 3.98 & -0.11 & 5.24 & 2.64 & -2.60 \\
Total range & 7.77 & 10.00 & 2.23 & 7.82 & 12.01 & 4.19 & 9.90 & 10.14 & 0.24 \\
Variance & 5.08 & 6.17 & -1.09 & 5.02 & 7.21 & 2.19 & 7.43 & 6.36 & -1.07 \\
Std Dev & 2.25 & 2.48 & -0.23 & 2.24 & 2.69 & 0.45 & 2.73 & 2.52 & -0.21 \\
N & 142 & 142 & 0.00 & 142 & 142 & 0.00 & 142 & 142 & 0.00 \\
\hline
\end{tabular}

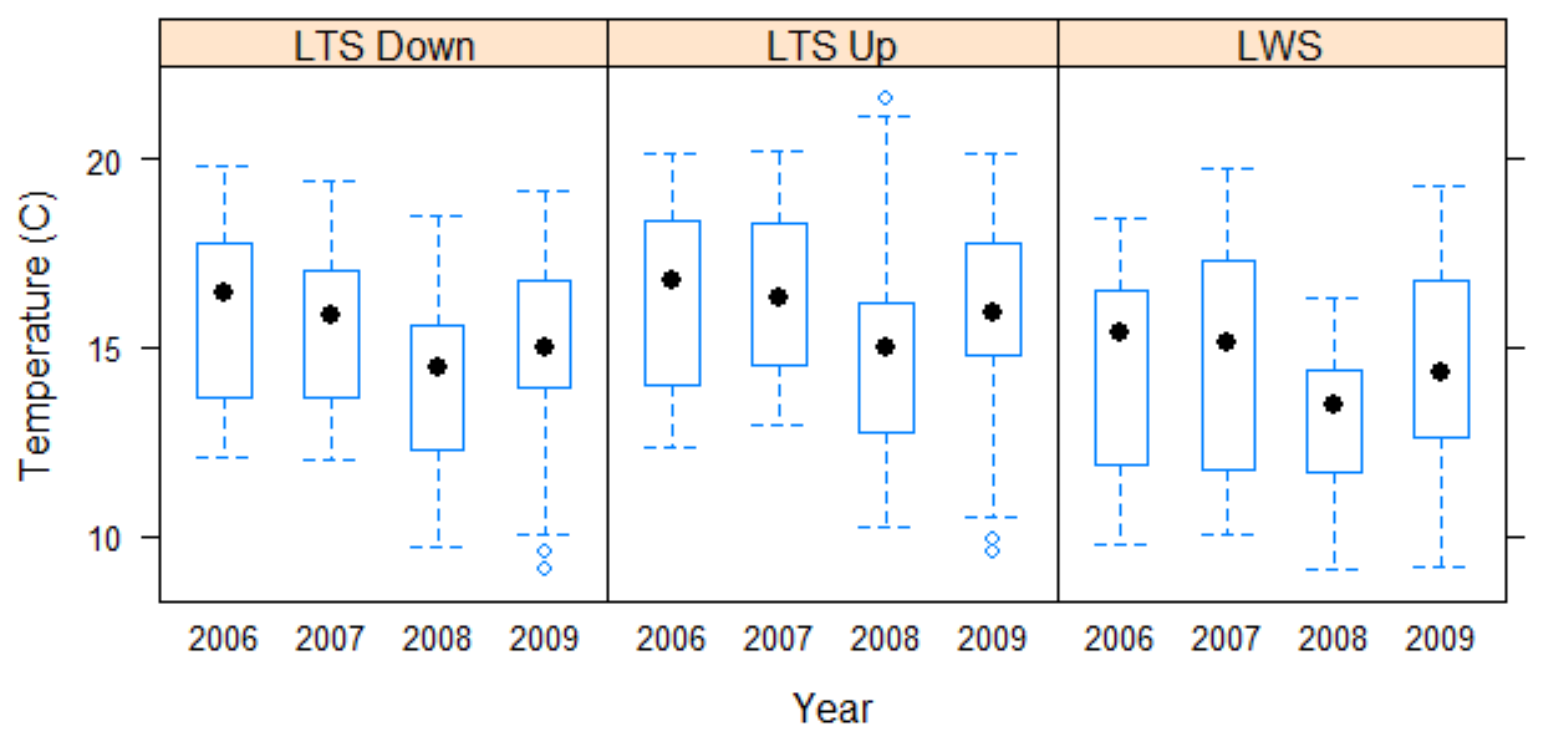

Figure 16. Boxplots of 7-DADM temperature $\left({ }^{\circ} \mathrm{C}\right)$ downstream, upstream and in LWS using all data collected from April $4^{\text {th }}$ to June $13^{\text {th }}$ for each year of the study. Tide gate replacement occurred between the 2007 and 2008 data collection periods. 


\subsection{Effects of Replacement on Fish Habitat in terms of Temperature}

\subsubsection{Daily Range}

Despite the increase in the total seasonal temperature range of $4.19^{\circ} \mathrm{C}$ and $2.23^{\circ} \mathrm{C}$ up and downstream of the gates respectively (Table 4), daily temperature range did not change significantly after the impact. On a daily basis, slough temperatures changed by $1.00-10.00^{\circ} \mathrm{C}$ downstream and in LWS, and total temperature range was 1.00 to a maximum of $7.00^{\circ} \mathrm{C}$, but usually closer to $3.00^{\circ} \mathrm{C}$ upstream (Figure 17). Figure 13 provides another illustration of the relative stability of upstream temperatures to the daily variability of temperature downstream. Though the total range increased slightly upstream after the impact, the change was almost imperceptible at the other two sites (Figure 17) and produced non-significant results via RIA (Table 5).

\subsubsection{Temperature-Depth}

The correlation coefficients for the temperature depth comparisons using the full set of hourly data from April $4^{\text {th }}$ to June 13th for each site are highly variable (Table 6). Figure 18 a) appears to have a relatively strong inverse correlation $(r=-0.60)$. Conversely, the correlation in Figure $18 \mathrm{~b}$ ) is weakly positive with an $\mathrm{r}$ value of 0.39 . Despite the long term positive trend, correlation values for distinct segments are negative, such as the temperature spike from May $15^{\text {th }}$ to the $22^{\text {nd }}$ with an $r$ value of -0.68 . The correlation values summarizing the season's data in Table 6 poorly represent the stronger negative correlations found within smaller segments of the data. The time plots in Figure 18 may be used to indicate the periods of stronger correlation.

\subsubsection{Temperature Exceedances}

Figure 19 indicates the number of days each year 7-DADM temperatures exceeded the $18^{\circ} \mathrm{C}$ standard for summer rearing habitat. In LWS, the threshold was surpassed 14 days before the impact and eight days afterwards (Table 7). Temperatures downstream of the tide gates exceeded the threshold 28 days before replacement and 18 days afterwards. Upstream, the number of days the threshold was exceeded decreased from over 42 days before replacement to 24 days after. Although the total number of days the temperature threshold was exceeded decreased upstream, it was consistently higher than at the other two sites. 


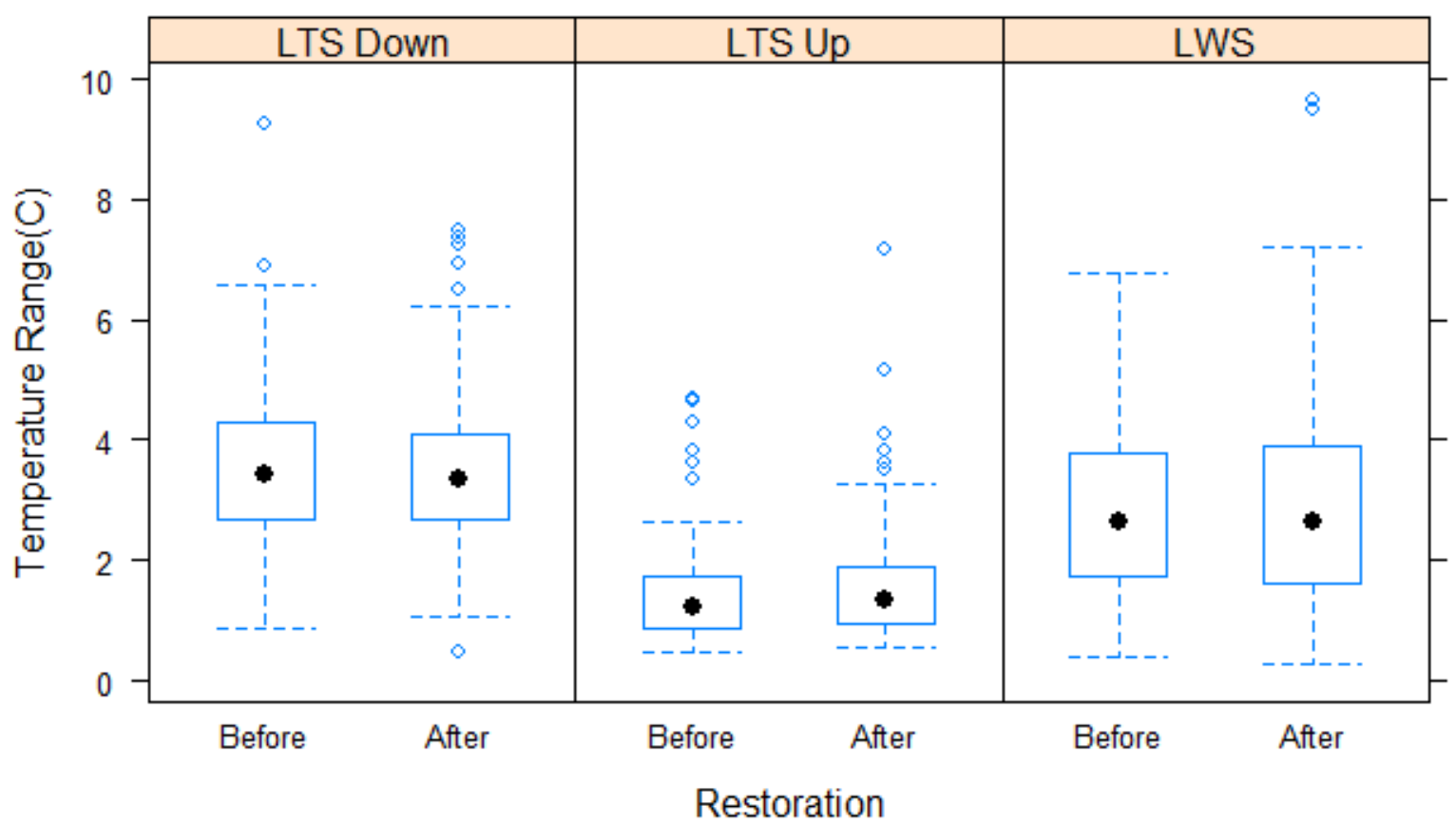

Figure 17. Boxplots of daily temperature range $\left({ }^{\circ} \mathrm{C}\right)$ before and after tide gate replacement (restoration) downstream and upstream of the gates and in LWS. Range was calculated by subtracting the daily minimum from the daily maximum to indicate the degree of temperature fluctuation at each site.

Table 5. Results from RIA significance test for comparisons between upstream-LWS and downstream-LWS using daily temperature range $\left({ }^{\circ} \mathrm{C}\right)$. Carpenter and others recommend a significance level of $\leq \mathbf{0 . 0 1}(1989)$.

\begin{tabular}{|l|c|c|}
\hline RIA & $\mathbf{2 0 0 6 - 2 0 0 9}$ & $\mathbf{2 0 0 6 - 2 0 0 9}$ \\
\hline & $\mathbf{p}$-value & $\mathbf{n}$ \\
\hline Up-LWS & 0.685 & 142 \\
\hline Down-LWS & 0.597 & 142 \\
\hline
\end{tabular}

Table 6. Spearman Rank Correlation r-values for hourly temperature and depth data collected between April $4^{\text {th }}$ and June $13^{\text {th }}$ of each year downstream, upstream and in LWS.

\begin{tabular}{|c|c|c|c|}
\hline Spearman & Downstream & Upstream & $\begin{array}{c}\text { LWS } \\
\text { (control) }\end{array}$ \\
\hline Year & $r$ & $r$ & $R$ \\
\hline 2006 & -0.23 & -0.60 & -0.16 \\
2007 & -0.25 & -0.87 & -0.17 \\
2008 & -0.11 & 0.39 & 0.01 \\
2009 & -0.12 & -0.01 & -0.06 \\
\hline
\end{tabular}



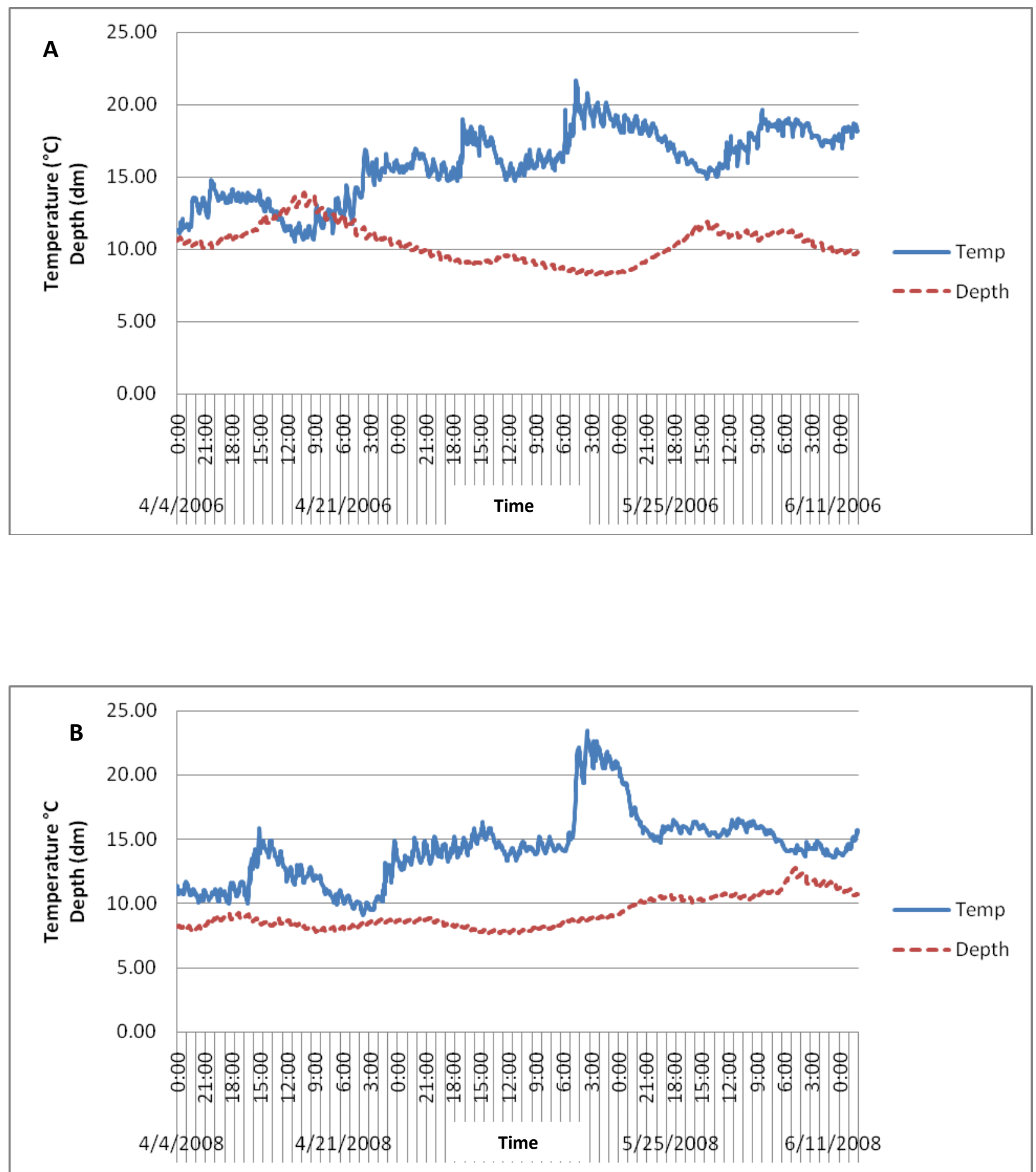

Figure $18 \mathrm{~A}$ and $\mathrm{B}$. Hourly temperature $\left({ }^{\circ} \mathrm{C}\right)$ and depth $(\mathrm{dm})$ data from upstream of the tide gates from the data collection period of April $4^{\text {th }}$ to June $13^{\text {th }}$ for 2006 (A) and 2008 (B). Years and sites selected to represent negative and positive correlations (see Table 7). 


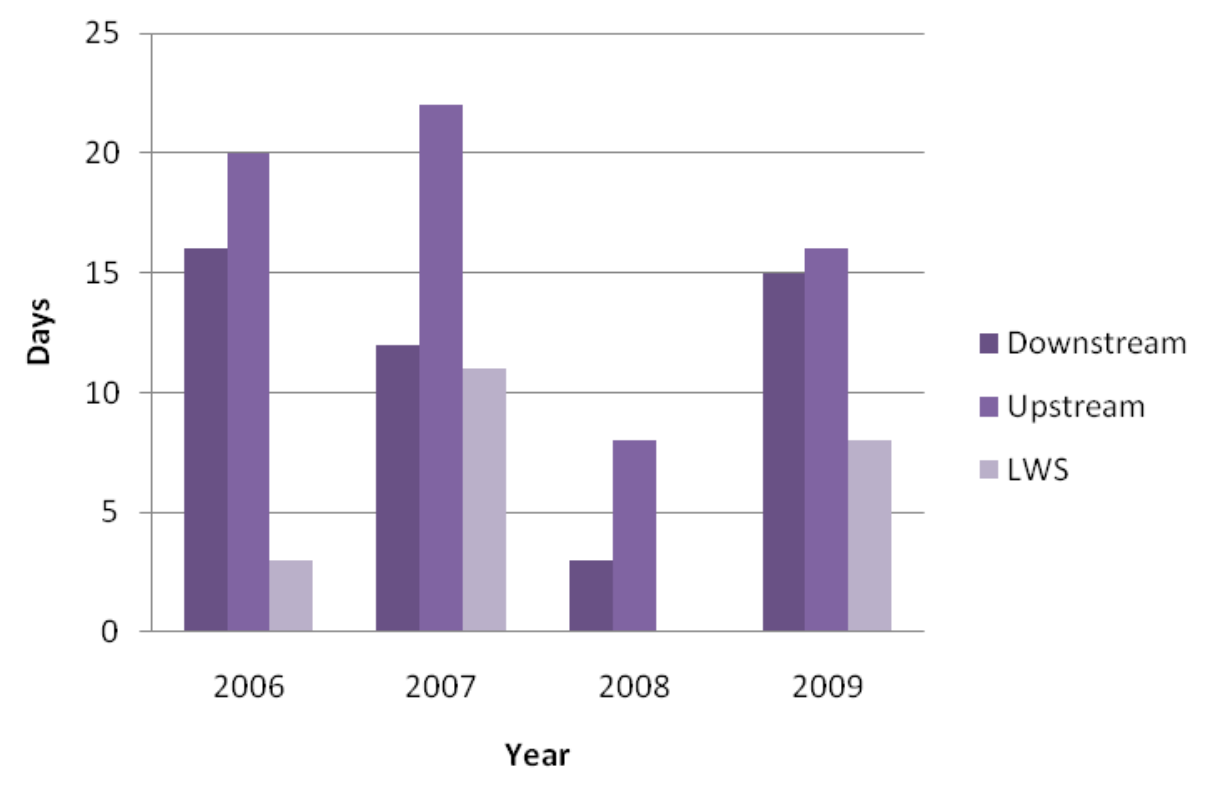

Figure 19. Number of days 7-DADM temperatures exceeded the EPA $18^{\circ} \mathrm{C}$ non-core summer rearing habitat standard for middle and lower reaches during the data collection period of 71 days between April $4^{\text {th }}$ and June $13^{\text {th }}$ for each site and for each year. The leftmost bar is downstream, followed by upstream and LWS. Tide gate replacement (the impact) occurred between 2007 and 2008.

Table 7. Number of days 7-DADM temperatures exceeded the EPA $18^{\circ} \mathrm{C}$ summer rearing habitat during the data collection period of 71 days between April $4^{\text {th }}$ and June $13^{\text {th }}$ for each site and for each year.

\begin{tabular}{llll}
\hline $\begin{array}{l}\text { \# Days 18 } \\
\text { exceeded }\end{array}$ & Before & After & Decrease \\
\hline Down & 28 & 18 & 10 \\
Up & 42 & 24 & 18 \\
LWS & 14 & 8 & 6 \\
\hline
\end{tabular}

\subsection{Natural Variability}

\subsubsection{Between Sites}

Figure 20 demonstrates the natural variability of temperature between sites.

Temperatures are generally lower in LWS, followed by downstream, and upstream with the highest temperatures. Very occasionally, later in the data collection period, temperatures in LWS surpass those downstream of the tide gates. Also notable is the temperature spike registered at all three sites in late May 2008, but experienced most extremely upstream of the gates. The high variability between sites is substantiated by the Monte Carlo results displayed in Table 8. Upstream and LWS were significantly different for all years and downstream and LWS 
were significant one year before and one year after the impact. Upstream and Downstream were not significantly different from each other except for 2007 when the p-value was 0.04 .

\subsubsection{Between Years}

Temperature was moderately variable from year to year with the greatest natural variability coinciding with the year of the impact. For the two years after the impact, temperatures were cooler at all sites. Temperatures were especially cool in 2008, but were also cooler in 2009. Figure 16 illustrates these trends as well as the decrease in the minimum temperatures up and downstream of the tide gates after replacement. The decrease of these minimum temperature values increases the total temperature range up and downstream of the gates so that these sites more closely resemble LWS. However, the possible outliers in 2009 suggest these lower temperatures occur infrequently limiting the resemblance of the impact sites to the control. The lower temperatures in 2008 were evident in the Monte Carlo results, which were significant for any comparison using data from this year (Table 9), indicating the high variability introduced by data from this year. Conversely, results from tests excluding data from 2008 were not significant, suggesting limited inter-annual variability between the other years of the study.

Table 8. Results from Monte Carlo significance test for comparisons between upstream-downstream, upstream-LWS and downstream-LWS using a sample size of 142 7-DADM temperature $\left({ }^{\circ} \mathrm{C}\right)$ values. Data were collected between April $4^{\text {th }}$ and June $13^{\text {th }}$ each year. A p-value $<0.05$ indicates a significant difference in temperature between sites.

\begin{tabular}{|c|c|c|c|c|}
\hline Monte Carlo & Up-Down & Up-LWS & Down-LWS & \\
\hline Year & p-value & p-value & p-value & $\mathrm{n}$ \\
\hline 2006 & 0.396 & 0.000 & 0.000 & 142 \\
2007 & 0.040 & 0.000 & 0.057 & 142 \\
2008 & 0.055 & 0.000 & 0.003 & 142 \\
2009 & 0.085 & 0.000 & 0.072 & 142 \\
\hline
\end{tabular}




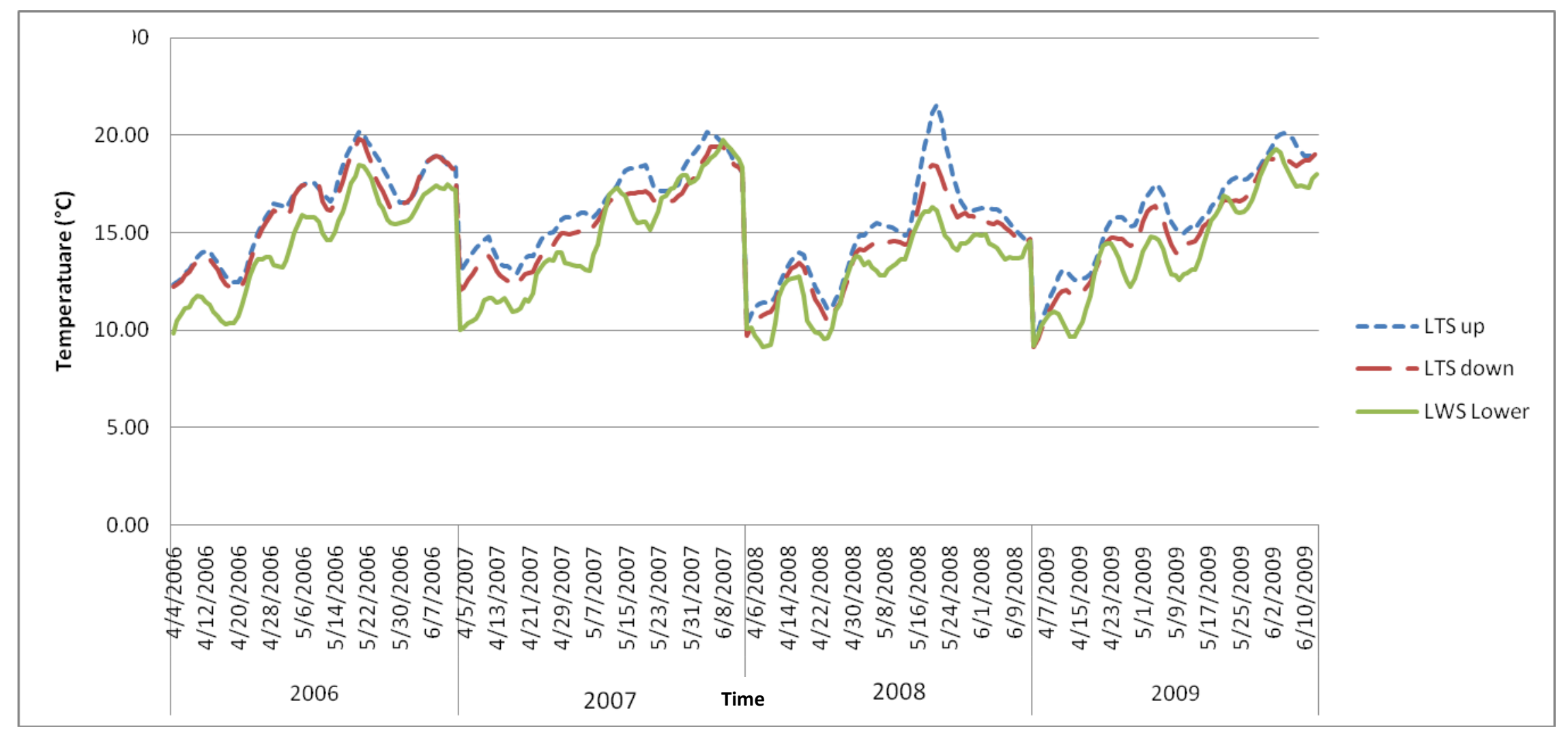

Figure 20. Time series plot for 7-DADM temperature $\left({ }^{\circ} \mathrm{C}\right)$ values for all years at all sites for the duration of the data collection period. Upstream temperatures are represented with a dashed line, downstream also has longer dashes and LWS is solid. 
Table 9. Results from Monte Carlo significance test for comparisons between years using a sample size of 142 7-DADM temperature $\left({ }^{\circ} \mathrm{C}\right)$ values for each test. Data were collected between April $4^{\text {th }}$ and $\mathrm{June}^{13^{\text {th }}}$ each year. A p-value $<0.05$ indicates a significant difference in temperature between years.

\begin{tabular}{|c|c|c|c|c|}
\hline & Downstream & Upstream & LWS (control) & \\
\hline Year & $\mathrm{p}$-value & $\mathrm{p}$-value & $\mathrm{p}$-value & $\mathrm{n}$ \\
\hline $2006-2007$ & 0.318 & 0.906 & 0.443 & 142 \\
$2006-2008$ & 0.000 & 0.010 & 0.000 & 142 \\
$2006-2009$ & 0.041 & 0.349 & 0.740 & 142 \\
$2007-2008$ & 0.000 & 0.000 & 0.000 & 142 \\
$2007-2009$ & 0.274 & 0.281 & 0.333 & 142 \\
$2008-2009$ & 0.007 & 0.015 & 0.001 & 142 \\
Before-After & 0.000 & 0.000 & 0.003 & 284 \\
\hline
\end{tabular}

\subsection{Other Variables Affecting Temperature}

Besides natural variability, ambient conditions also influenced water temperatures. The matrix in Figure 21 illustrates the data distribution of a single variable along the diagonal from upper left to lower right and the Spearman Rank correlation values and plots are placed at the intersection of two variables. Temperatures up and downstream of the tide gates, were highly correlated between these two sites $(r=0.99)$. The greatest difference in their response came from the comparison with LWS, which explained slightly more of the variability downstream than up, with respective r-values of 0.96 and 0.94. Temperature in Clifton Channel correlates strongly with water temperature in LWS with an r value of 0.97 , relative to up and downstream with $\mathrm{r}$ values of 0.93 .

Apart from temperatures of adjacent water bodies, air temperature was the single most important factor explaining $86 \%$ of the variation in water temperature up and downstream of the tide gates and $82 \%$ of the temperature variation in LWS (Figure 21). The correlation between discharge and temperature at the various sites was relatively low, with $r$ values of 0.40 or less up and downstream and less than 0.35 for Clifton and LWS. Precipitation had a very low correlation with the other variables, the highest being an $r$ value of 0.21 with air temperature. 


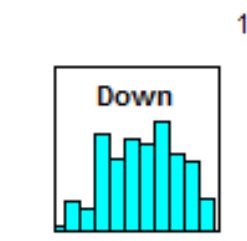

$\begin{array}{llll}10 & 14 & 18 & 22\end{array}$
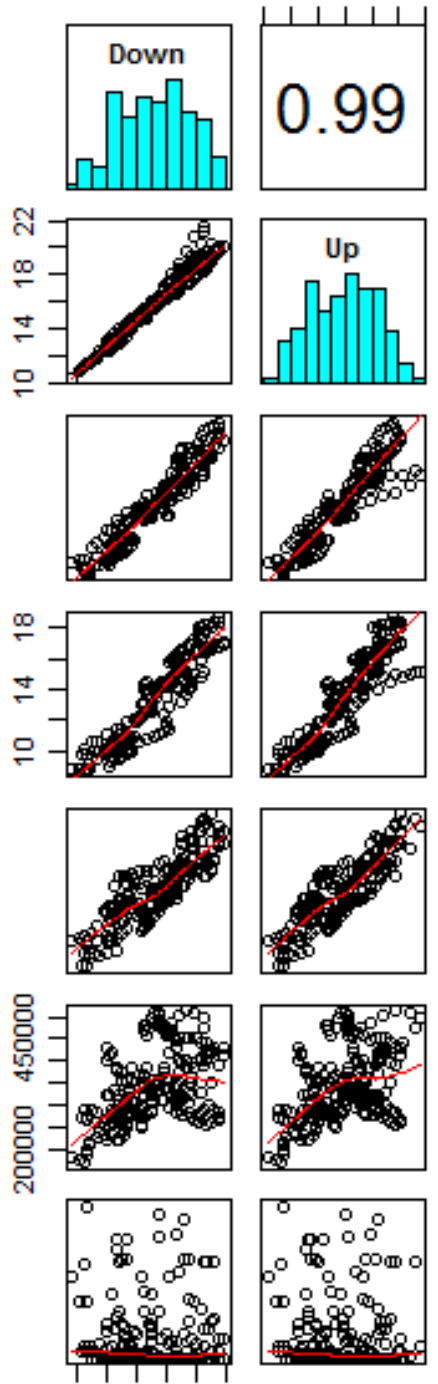

$10 \quad 14 \quad 18$
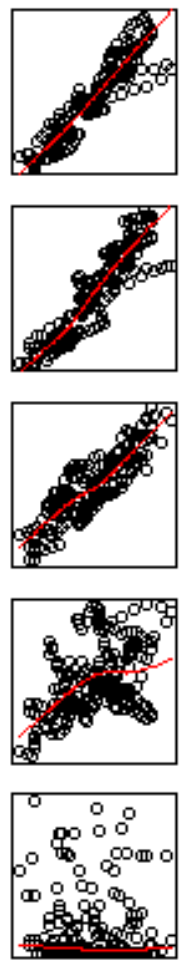
政

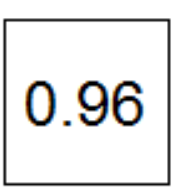

$\begin{array}{lll}10 & 14 & 18\end{array}$
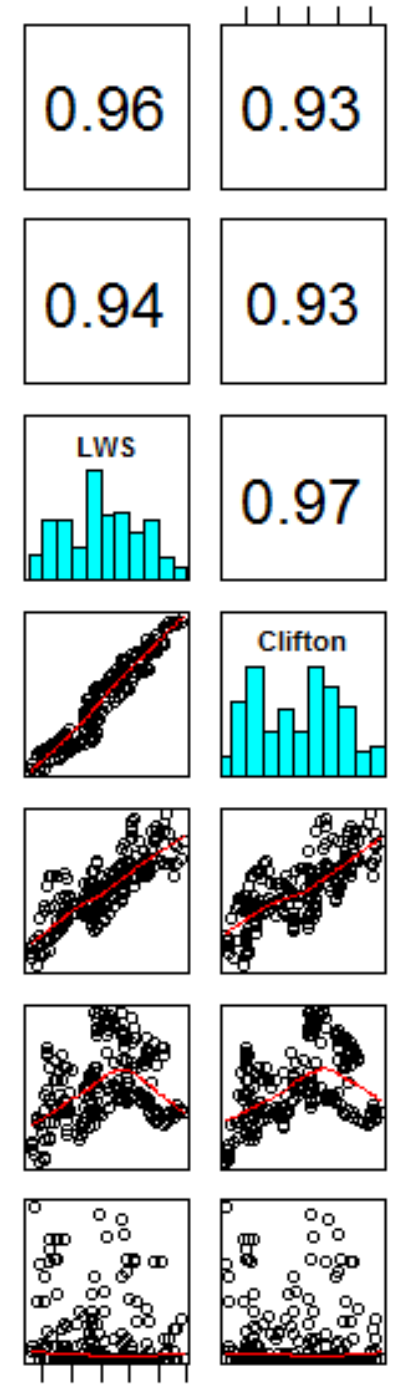

$\begin{array}{lll}10 & 14 & 18\end{array}$
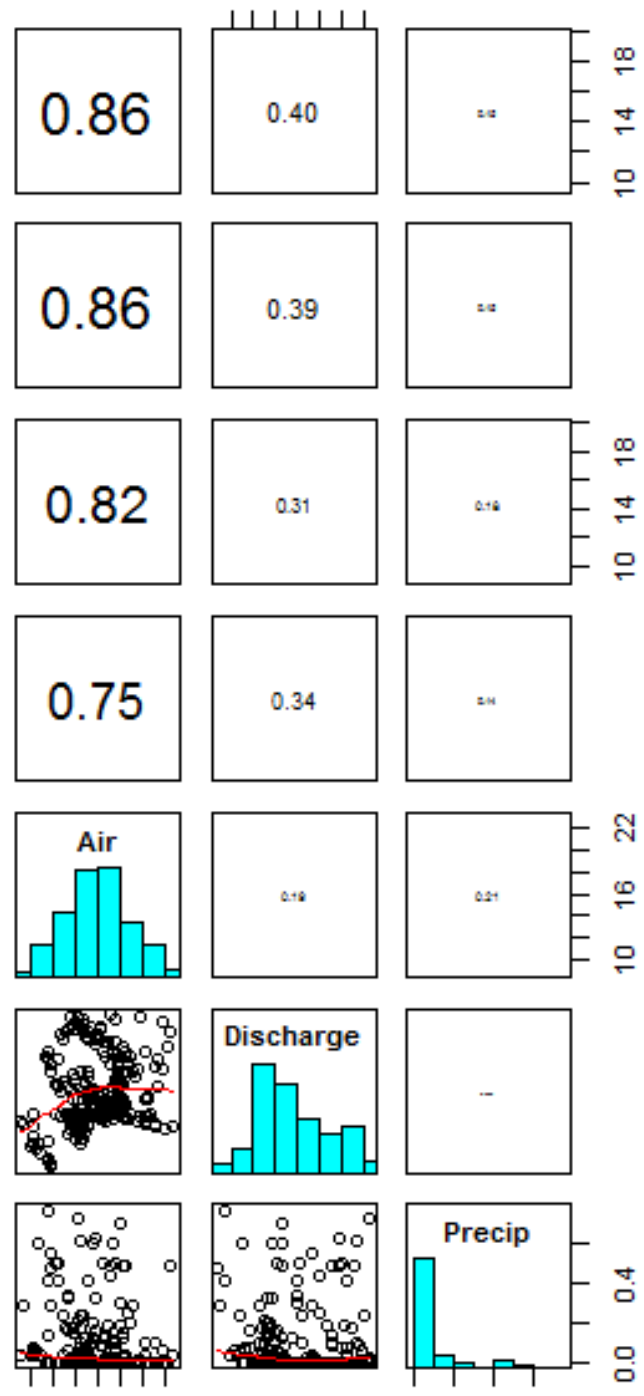

$\begin{array}{lll}10 & 16 & 22\end{array}$

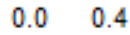

Figure 21. Spearman Rank Correlation matrix for all variables from 2006-2008 (Precipitation data were not available for 2009). The variables are displayed with the distribution of their on the middle diagonal from upper left to lower right: Upstream, downstream, LWS Clifton Channel and air are 7-DADM temperature values $\left({ }^{\circ} \mathbf{C}\right)$, daily Columbia River discharge (Cubic Feet per Second) and daily precipitation (in). On the lower left of the matrix, the intersection of two variables displays the correlation plot and the intersection in the upper right indicates the correlation, r-value. Higher $r$-values are larger indicating a stronger correlation. 


\subsection{Discussion}

\subsection{Effect of Tide Gate Replacement on Water Temperature}

Despite a general downward trend in the data, the analyses indicate the new tide gates did not have a significant effect on water temperature. This result became evident in the varied results from the RIA significance tests and the temperature decrease that occurred at all sites. RIA produced non-significant results for the comparison between the primary impact site, upstream, and LWS, and significant results for the downstream-LWS comparison (Table 5). Additionally, temperatures decreased evenly at all sites after replacement, including the control. Because the RIA results were not consistent between sites, and the temperature decrease occurred universally at all sites, this change cannot be attributed to the new tide gates. A la Niña event that occurred during the data collection period in 2008, after tide gate replacement, caused the decrease in ambient temperatures. La Niña is determined by a $-0.5^{\circ} \mathrm{C}$ variation in the Ocean Niño Index for a three month period (NWS CPC 2009). Because RIA analyzes the change in the difference between sites and not the actual temperatures, the results were not biased by the change in ambient conditions that affected both the impact and control sites evenly (Carpenter and others 1989).

Although the analysis indicates the new tide gates had no significant effect on temperature, the minimum temperatures up and downstream of the gates decreased after installation. The primary change the new gates introduced into the system was an increase in the frequency, duration and width of openings during ebb tides (Ennis 2008), increasing the number of salmon detected by USFWS PIT tag antennas entering the slough (unpublished data). A possible explanation of the decrease in minimum temperatures is an increase in circulation as a result of the new gates.

The old gates opened less frequently due to the high hydraulic pressure required to open them and probably released a smaller total volume of water than the new gates. The top-hinged design drained cooler water from deeper parts of the slough, leaving warmer surface water to absorb more solar radiation upstream. The wider, longer and more frequent openings of the new gates may have increased slough drainage, including warmer surface waters. In this case, the rate of seepage upstream through the dike may also have increased due to greater hydraulic pressure from the WSE differential during high tide, increasing the rate of recharge to the slough. 
Higher rates of outflow and recharge may have increased slough circulation, approaching the tidal dynamics of a natural slough.

The limited literature available on the effects of tide gates on temperature, suggests that new tide gates must allow inflow to decrease upstream temperatures. Studies on Blind Slough in Tillamook Bay, Oregon, and Fisher's Slough in Skagit Basin, Washington, with conditions similar to LTS with the old tide gates, experienced temperatures $2-5^{\circ} \mathrm{C}$ warmer upstream than downstream. Once these gates were either replaced or managed to allow inflow, upstream temperatures decreased by $1-4^{\circ} \mathrm{C}$ (Giannico and Souder 2005, Tonkin 2009).

Tide gates on LTS did not allow inflow for the data collection periods between March and June for all years of the study, providing little basis for comparison. Mean differences in temperature up and downstream of the tide gates were less than $1^{\circ} \mathrm{C}$ both before and after replacement (Table 4) and Monte Carlo results comparing these two sites produced nonsignificant results for three out of four years (Table 8). Two of these non-significant results however, approached significance with p-values of $<0.09$, indicating high variability between the temperature regimes at each site. Figure 13 supports this observation illustrating the higher temperature steady state upstream relative to downstream where temperatures were more varied.

\subsection{Effects of Replacement on Fish Habitat in terms of Temperature}

Though the changes in 7-DADM temperatures after replacement did not test as significant in the RIA analysis, changes in the maximum and minimum temperatures in LTS may have occurred as a result of the new gates. RIA compares the mean temperature values, consequently, changes in the extremities are not detected via this method. Though not statistically significant, these changes may be meaningful for salmon. The three different strategies I used to examine how the extreme temperature values affect salmon: daily range, temperature-depth correlation, and temperature exceedances provided moderately more information. The lower minimum temperature values after replacement increased the seasonal temperature range but not the daily range. Varied correlation values for seasonal temperature and depth obscured stronger correlations within segments of the data, the latter suggesting water depth has a meaningful effect on temperature. The number of temperature Exceedances 
upstream decreased after replacement, possibly as a combined effect of the cooler temperatures during la Niña and the lower minimum temperatures.

\subsubsection{Daily Range}

The increase in total seasonal temperature range did not correspond to an increase in total daily range. The lower minimum temperatures in Figure 15 appear as possible outliers in Figure 16, suggesting they occur infrequently. Though salmon are not experiencing lower temperatures on a daily or even frequent basis, the presence and growth rate of a salmon and one that oversummered in LTS, suggest the habitat may be suitable for rearing. Little can be inferred from a single fish, however that it survived the summer indicates the presence of thermal refugia and ample forage. Because temperature data came from a single location, the presence and distribution of refugia is unknown. Studies indicate that warmer temperatures increase salmonid metabolic rate, resulting in rapid growth with the availability of adequate forage (Pool and others 2001). The high growth rates of the specimens captured in LTS suggests that forage supply was sufficient to accommodate the higher metabolic rates caused by higher temperatures.

\subsubsection{Temperature-Depth}

The new tide gates may have had an effect on temperature extremes in both directions. In both Larson Slough in Coos Bay, Oregon, and in Gannon Slough in Humbolt Bay, California, new gates increased the rate of drainage relative to the rate of recharge, and slough temperatures upstream of the gates increased after replacement (Coos Watershed Association 2006, Turner 2005). Water Surface Elevation upstream in LTS did not fluctuate as extremely as in these sloughs, although the results from the Spearman rank correlation analysis suggest a correlation between water temperature and depth. Though the results from these analyses for data from an entire season were varied, $r$ values were generally negative indicating temperature increases with decreasing depth. Smaller data segments, selected via visual inspection of the time series plots in Figure 18, revealed stronger correlations. Though temperature and depth data had an overall positive correlation in 2008, data selected during the temperature spike in late May was strongly negative with an $r$ value of -0.68 .

\subsubsection{Temperature Exceedances}

The number of Exceedances decreased after the impact at all sites. Relative to the decrease of 6 days in LWS, up and down stream exceedances decreased by 18 and 10 days 
respectively. In addition to the influence of La Nina, the decrease in temperature exceedances may also have been affected by the decrease in minimum temperatures. Though the EPA temperature thresholds for salmon provide a guideline, the category may not be relevant to the conditions at the study site. The EPA (2003) categorizes middle and lower reaches of a watershed as "non-core" rearing habitat with a threshold of $18^{\circ} \mathrm{C}$ and middle upper reaches as core rearing habitat with a lower temperature threshold of $16^{\circ} \mathrm{C}$. The EPA guidelines may refer to smaller systems than the Columbia. Although the study site is low in the watershed, recent research indicates estuaries provide core rearing habitat (Bottom 2005) and slightly warmer temperatures may be acceptable provided adequate forage (Pool and others 2001).

\subsection{Natural Variability}

\subsubsection{Between sites}

Another source of variability is confounding factors that affect each site differently. According to the Monte Carlo test results, each site at some point during the study period was significantly different from the other two sites (Table 8). Upstream of the tide gates is heavily influenced by the affects of grazing and tide gate operation. The grazing has a net warming effect on slough temperatures. In many areas, overhanging riparian vegetation has been removed to provide cattle with access to the slough, resulting in a loss of shade cover and warmer temperatures. Trampling by cattle causes bank erosion and increases in turbidity with subsequent increases in temperature. Nutrient loading from the manure increases algal production, which absorbs solar radiation and heats the water. Downstream of the gates is influenced by outflow from upstream and dynamics in Clifton Channel, while LWS is completely subject to unimpeded flow and temperature regimes in Clifton Channel and the Columbia River. Each of these factors may have varying influence from year to year. Without monitoring them directly it is difficult to attribute variability in the data to any particular cause, including new tide gates.

\subsubsection{Between years}

An abrupt decrease in temperatures was evident in all sites in 2008 after the tide gate replacement (Figure 8), largely due to a la Niña event. Temperatures were also cooler in 2009 than they had been in 2006 and 2007, although not as extreme as in 2008. Though the cooler 
temperatures in 2008 and 2009 were evident at all sites, the effect of the cooler temperatures was stronger upstream and downstream of the gates, where minimum temperatures decreased by four times as much as they did in LWS (Figure 15, Table 4). While the cooler temperatures of 2008 and 2009 cannot be attributed to the new tide gates, additional data would indicate whether the minimum temperatures remained lower relative to before replacement.

\subsection{Other Variables Affecting Temperature}

The results of the correlation analysis in Figure 21 were fairly intuitive regarding the influence of different variables on slough water temperature. Predictably, up and downstream temperatures were highly correlated with an r-value of 0.99 . The correlation between downstream and LWS was slightly stronger than upstream, due to the greater connectivity of these two systems. Similarly, the greater correlation between LWS and Clifton is logical as both are subject to the natural tide cycle without impediment. Given the stagnation that occurs up and downstream of the tide gates, it is not surprising that air temperature has a greater influence in these sites as compared to LWS, which is regularly flushed by the tides. The stronger correlation of discharge at the up and downstream sites relative to LWS and Clifton may again be attributed to decreased tidal influence at these sites.

\subsection{Limitations of the Study}

Factors that may have influenced the results include the study design and the analytical methods. BACI is a robust design capable of detecting changes in ecosystem scale studies. Its strength lies in the inclusion of two sources of data for comparison: from before the impact and from a control site. If analyses detect a change in the impact site after the manipulation, the change may, if all assumptions are met, be attributed to the impact (Carpenter and others 1989). However, natural variability affecting the impact and reference sites unevenly, can bias the outcomes. Underwood (1992) recommends including more than one control site to remedy this problem. Additional control sites provide an indication of the natural range of variability within the system enabling the researcher to better distinguish a response to the impact from natural variability. The high degree of variability between the control and the impact sites and between 
years may have obscured any effect on temperature the new tide gates may have had. Given the magnitude of the scale of the tide gate replacement, additional control sites were not available.

Non-parametric analyses suited the data better than parametric methods due to their irregular distributions and the dependence resulting from the time series element of the data. Assumptions for RIA and Monte Carlo are similar and include: data points paired in time, avoiding serial and spatial autocorrelation, and fairly equal variance between impact and control sites. The first assumption was met precisely with loggers programmed to record temperature on the hour. Autocorrelation may have been introduced by the time series data and the location of the control site. To reduce serial autocorrelation, data were transformed into 7-DADM and spatial autocorrelation was reduced by the distance of nearly $2 \mathrm{~km}$ that separated the control and impact sites. The minimum variance was $5.02^{\circ} \mathrm{C}$ upstream, and the maximum $7.34^{\circ} \mathrm{C}$ in $\mathrm{LWS}$ before replacement (Table 4), however neither Carpenter and others (1989) nor Stewart-Oaten and others (1986) provide an indication as to whether this difference in variance of $2.32^{\circ} \mathrm{C}$ was within an acceptable range.

\subsection{Management Implications and Recommendations}

The new gates, as operated with fish orifices closed, increased salmon passage and possibly decreased minimum temperatures in the slough. Wild Chinook salmon were captured in the slough after replacement, indicating greater ingress. Growth rates for released PIT-tagged salmon exceeded growth rates at the Spring Creek Fish Hatchery (Johnson, personal communication). The high growth rate suggests ample forage in the presence of warmer conditions, as compared to the cooler water temperatures at the hatchery. Water temperatures during the data collection period from March $29^{\text {th }}$ to June $13^{\text {th }}$ were generally suitable for fish for all years. Mean and median 7-DADM temperatures hovered around $16^{\circ} \mathrm{C}$ (Table 2) meeting the EPA's threshold for core rearing habitat, although temperatures increased in the summer occasionally reaching $20^{\circ} \mathrm{C}$, at which temperature juveniles may begin to experience sublethal effects (Poole and others 2001). In 2009, temperatures remained above $20^{\circ} \mathrm{C}$ from late July to early September, and reached a peak of $23^{\circ} \mathrm{C}$ for a week in early August.

Although warmer temperatures can increase growth rates in the presence of ample forage, temperatures above $20^{\circ} \mathrm{C}$ can also be lethal in the absence of thermal refugia or easy egress. 
Results from this study and the literature indicate that increased tidal inflow serve to increase salmon passage and tidal circulation, causing a corresponding reduction in temperature, all of which are desirable conditions for productive rearing habitat. Flow dynamics in LTS should be modeled to determine an acceptable rate of inflow so that one or more of the fish orifices can be left open on a long term basis. Two years of additional data collection with the orifices open would provide an indication of the effect of increased tidal inflow on temperature and a balanced comparison for the data from the two years prior to replacement. Because tide gate replacement is minimally effective relative to dike removal as a restoration strategy, it is critical to optimize the potential of the outcome. Once in place, tide gate operations should simulate a natural slough to the extent possible within the limitations of the site. 


\subsection{Literature Cited}

AccuWeather. 2009. Cathlamet, WA, Typical Weather. [Updated 2009 Sept 11, cited 2009 Sept 11]. Available from: http://www.accuweather.com/us/wa/cathlamet/98612/forecastnormals.asp?partner $=$ accuweather\&traveler $=0 \&$ zipChg $=1 \&$ metric $=0$

Allan J. 1994. Stream ecology: structure and function of running waters. Boston: Kluwer Academic Publishers.

Anisfeld S, Benoit G. 1997. Impacts of flow restrictions on salt marshes: an instance of acidification. Environmental Science and Technology, 31(6):1650-1656.

Agardy T, Alder J. 2005. Coastal Systems. Chapter 19 in Hassan R, Scholes R, Ash N, editors. Millennium Ecosystem Report: Ecosystems and Human Well Being. Washington DC: Island Press, pp 1-37.

Barendregt A, Whigham D, Meire P, Baldwin A, Van Damme S. 2006. Wetlands in the tidal freshwater zone. Ecological Studies, 191:117-148.

Bass, A. 2006. Lower Columbia River Study. Report for Native Fish Society and Willamette River keeper.

Beamer E, LaRock R. 1998. Fish use and water quality associated with a levee crossing the tidally influenced portion of Browns Slough, Skagit River Estuary, Washington. Report to Skagit County Diking District No. 22.

Beck N, Fisher A, Bruland K. 2001. Modeling water, heat and oxygen budgets in a tidally dominated estuarine pond. Marine Ecology Press Series, 217:43-58.

Bottom D [Internet]. Salmon Life Histories, Habitats, and Food Webs in the Columbia River Estuary. Portland, OR: NW Power and Conservation Council; [Updated 2008; cited 2009 Sept 2] Available from: http://www.nwcouncil.org/fw/program/2008amend/spe/history.pdf.

Bottom D, Riddell B, Lichatowich J. 2006. The estuary, plume and marine environments. Chapter 10 in R. N. Williams (ed.) Return to the River, Elsvier Academic Press, San Diego, CA.

Bottom D, Simenstad C, Baptista A, Jay D, Burke J, Jones K, Casillas E, Schiewe M. 2005. Salmon at river's end: The role of the estuary in the decline and recovery of Columbia River salmon. U.S. National Marine Fisheries Service. Seattle, Washington.

Boumans R, Burdick D, Dionne M. 2002. Modeling habitat change in salt marshes after tidal restoration. Restoration Ecology, 10(3):543-555. 
Brophy L [Internet]. Tidal wetland prioritization for the Siuslaw River Estuary. Report to Siuslaw Watershed Council. Corvallis, OR: Green Point Consulting; [Updated 2005; cited 2009 Sept 2]. Available from http://www.greenpointconsulting.com.

Carpenter S, Thomas F, Heisey D, Kratz T. 1989. Randomized intervention analysis and the interpretation of whole ecosystem experiments. Ecology, 70(4)1141-1152.

Charland, J. Reconnaissance Survey of Tide Gates in Tillamook Bay Vicinity. Tillamook Bay National Estuary Partnership, Garibaldi, OR. [cited 2009 Sept 3]. Available from: www.oregon.gov/OWEB/MONITOR/docs/mr_ReconnaissanceSurveyofTidegates.pdf

[CMOP] Center for Coastal Margin Observation and Prediction [Internet]. Data Inventory for Tenasillahe Island; [Updated 2009 Oct 1; cited 2009 Oct 2]. Available from: http://www.ccalmr.ogi.edu/CORIE/data/publicarch/tnslh/.

Coos Watershed Association [Internet]. Tide gate replacement project-effectiveness monitoring report. Coos Bay, OR: Coos Watershed Association; [Updated 2006; cited 2009 Sept 2]. Available from: http://www.cooswatershed.org/Publications/204-289_final_report.pdf

Cornu C, Sadro S. 2002. Physical and functional responses to experimental marsh surface elevation manipulation in Coos Bay’s South Slough. Restoration Ecology, 10(3):474486.

Crooks S, Schutten G, Sheern K, Pye, Davy A. 2002. Drainage and elevation as factors in the restoration of salt marsh in Britain. Restoration Ecology, 10(3):591-602.

Diefenderfer H, Roegner G, Thom R, Dawley E, Whiting A, Johnson G, Sobocinski K, Anderson M, Ebberts B. 2005. Evaluating Cumulative Ecosystem Response to Restoration Projects in the Columbia River Estuary. PNNL -15102. Draft Report to the US Army Corps of Engineers, Portland District, by Pacific Northwest National Laboratory, Richland, Washington.

Ennis, S (unpublished). Hydraulic pressure differential and tide gate opening dynamics on Large Tenasillahe Island in the Lower Columbia River.

Fairbridge, R. 1980. The estuary: its definitions and geodynamic cycle. In Olaussen E, Cato I, editors. Chemistry and biogeochemistry of estuaries. New York: Wiley, pp 1-35.

Frenkel R, Morlan J. 1991. Can we restore our salt marshes? Lessons from the Salmon River, Oregon. Northwest Enviornmental Journal, 7:119-135.

Giannico G, Souder J. 2004. The effects of tide gates on estuarine habitats and migratory fish. Oregon State University.

Giannico G, Souder J. 2005. Tide Gates in the Pacific Northwest. Oregon State University. 
Good J [Internet]. Estuarine science, management and restoration. Corvallis, OR: Oregon State University Extension Service; [Updated 1999; cited 2009 Sept 2]. Available from: http://www.oregon.gov/DSL/SSNERR/docs/WSEP.pdf

Gray A, Simenstad C, Bottom D, Cornwell T. 2002. Contrasting functional performance of juvenile salmon habitat in recovering wetlands of the Salmon River Estuary, Oregon, U.S.A. Restoration Ecology, 10(3):514-526.

Gregory R, Levings C. 1998. Turbidity reduces predation on migrating juvenile pacific salmon. Transactions of the American Fisheries Society 127:275-285.

Green R. 1979. Sampling design and statistical methods for environmental biologists. Wiley: New York.

Havens K, Varnell L, Watts B. 2002. Maturation of a constructed tidal marsh relative to two natural reference marshes over 12 years. Ecological Engineering, 18:305-315.

Johnson G, Ebberts B, Thom R, Ricci N, Whiting A, Southard J, Sutherland G, Wilcox J, Berquam T. 2003. An Ecosystem-Based Approach to Habitat Restoration Projects with Emphasis on Salmonids in the Columbia River Estuary. Prepared by: Pacific Northwest National Laboratory. PNNL-14412; [Updated 2009 Aug; cited 2009 Sept 3]. Available from: http://www.pnl.gov/main/publications/external/technical_reports/PNNL-14412.pdf

Johnson J, Poirier J, Whitesel T. 2007. Lower Columbia River Improvement: Assessment of Salmonid Populations and Habitat on Tenasillahe and Welch Islands, 2006 Project Report. Prepared by the Columbia River Fish Program Office of US Fish and Wildlife, Vancouver WA; [Updated 2009 Aug 28; cited 2009 Sept 3]. Available from: http://www.fws.gov/columbiariver/publications/Johnson_Tenasillahe_2007.pdf

Jones R, Kelso D. 2008. Spatial and seasonal patterns in water quality in an embayment-main reach of the tidal freshwater Potomac River, USA: a multiyear study. Environmental Monitoring and Assessment 147:351-375

Korstrom J, Birtwell I. 2006. Effect of suspended sediment on the escape behavior and coverseeking response of juvenile Chinook salmon in freshwater. Transactions of the American Fisheries Society 135:1006-1016.

Lucas L, Sereno D, Burau J, Schraga T, Lopez C, Stacey M, Parchesvky K, Parchevsky V. 2006. Intradaily variability of water quality in a shallow tidal lagoon: mechanisms and implications. Estuaries and Coasts, 29(5):711-730.

MacBroom J. 2000. Tidal Marsh Restoration. OCEANS 2000 MTS/IEEE Conference and Exhibition; 2000 Sept 11-14, Providence, RI. 3: 1925-1928.

Manly B. 2008. Statistics for environmental science and management. New York: Chapman and Hall/CRC. 
Maris T, Cox T, Temmerman S, De Vleeschauwer P, Van Damme S, De Mulder T, Van den Bergh E, Meire P. 2007. Turning the tide: creating ecological conditions for tidal marsh development in a flood control area. Hydrobiologia, 588: 31-43.

Miller J, Simenstad C. 1997. A comparative assessment of a natural and created estuarine slough as a rearing habitat for juvenile Chinook and Coho salmon. Estuaries, 20 (4): 792-806.

Mitchell T, Mitchell K, LovellFord R, Klein L. 2005. Fornsby Creek Project: Self-regulating tidegates and estuary restoration. Proceedings of the Puget Sound Georgia Basin Research Conference; 2005 Mar 29-31; Seattle WA. [Cited 2009 Sept 3]. Available from: http://www.swinomish-nsn.gov/departments/planning/water/publications/P3_MITCH.pdf

Murphy S, Voulgaris G. 2006. Identifying the role of tides, rainfall and seasonality in marsh sedimentation using long-term suspended sediment concentration data. Marine Geology, 227: $31-50$.

National Research Council. 2004. Managing the Columbia River: instream flows, water withdrawals, and salmon survival. Washington DC: National Academies Press.

Neckles H, Dionne M, Burdick D, Roman C, Buchsbaum R, Hutchins E . 2002. A monitoring protocol to assess tidal restoration of salt marshes on local and regional scales. Restoration Ecology, 10(3):556-563.

[NOAA] National Oceanic and Atmospheric Administration [Internet]. Our Restless Tides. [Updated: 1998; cited 2009 Sept 2]. Available from: http://www.co-ops.nos.noaa.gov/restles 1.html

[NOAA] National Oceanic and Atmospheric Administration [Internet]. Historic Tide Data, Skamokawa, Washington. [Update: 2009 Sept 3; cited 2009 Oct 2]. Available from: http://www.coops.nos.noaa.gov/data_menu.shtml?stn=9440569\%20Skamokawa,\%20WA\&type=Historic+Tide + Data

[NPCC] Northwest Power and Conservation Council. 2005. Pocket Guide: Fast Facts About the Columbia River Basin. Portland OR: NPCC.

[NWS CPC] National Weather Service, Climate Prediction Center [Internet]. 2009. Cold and Warm Episodes by Season, Changes in the Oceanic Nino Index (ONI). [Updated 2009 Apr 4; Cited 2009 Oct 1]. Accessed from: http://www.cpc.noaa.gov/products/analysis_monitoring/ensostuff/ensoyears.shtml

Odum W. 1988. Comparative Ecology of tidal freshwater and salt marshes. Annual Review of Ecology and Systematics, 19:147-176. 
Oberrecht K [Internet]. 2002. Salmon in the Estuary. South Slough National Estuary Research Reserve, Charleston, OR. [Updated 2009 Mar 16; Cited 2009 Sept 3]. Access from: http://www.oregon.gov/DSL/SSNERR/docs/EFS/EFS30salmon.pdf

Onset [Internet]. 2008. HOBO U20 Water Level Logger, Onset Corp., Pocasset, MA. [Cited 2009 Sept 3]. Available from: www.onsetcomp.com/files/manual_pdfs/12315_C_MAN_U20.pdf.

[OR DEQ] Oregon Departument of Environmental Quality. 1998. Oregon's final 1998 water quality limited streams 303(d) list. [Updated 1998 Nov 5; cited 2009 Sept 3]. Accessed from: http://www.deq.state.or.us/WQ/assessment/docs/rpt98.pdf accessed 12/8/2008.

Osler M, Ruthven T, Ramsey J [Internet]. Green Harbor River tidal hydraulics study. Report by Applied Coastal Research and Engineering, Inc., Mashpee MA. [Updated 2007 Mar; cited 2009 Sept 3]. Available from: http://www.townofmarshfield.org/ Public_Documents/MarshfieldMA_Conservation/Green\%20Harbor\%20River\%20Hydrau lics\%20Report.pdf

Park G, Park S. 2000. Long-term trends and temporal heterogeneity of water quality in tidally mixed estuarine waters. Marine Pollution Bulletin, 40(12):1201-1209.

Pollock M, Pess G, Beechie T, Montgomery D. The importance of beaver ponds to Coho salmon production in the Stillaguamish River Basin, Washington, U.S.A. North American Journal of Fisheries Management, 24:749-760.

Porior D [Internet]. Design of tide gate for stream simulation. Coos Bay, OR: Porior Engineering; [Updated 2003; cited 2009 Sept 2] Available from: http://www.porior.com/homepage/tidegates.pdf.

Poole G, Dunham J, Hicks M, Keenan D, Lockwood J, Materna E, McCullogh D, Mebane C,. Risley J, Sauter S, Spalding S, Sturdevant D. 2001. Technical Synthesis: Scientific issues relating to temperature criteria for salmon, trout and char native to the Pacific Northwest. EPA 910-R-01-007.

Portnoy J, Giblin A. 1997. Effects of historic tidal restrictions on salt marsh sediment chemistry. Biogeochemistry, 36:275-303.

Portnoy J. 1999. Salt marsh diking and restoration: biogeochemical implications of altered wetland hydrology. Environmental Management, 24(1):111-120.

Rheinhartd R. 2007. Tidal freshwater swamps of a lower Chesapeake Bay subestuary. Pages 161-181 in Conner W, Doyle T, and Karuss K, editors. Ecology of Tidal Freshwater Forested Wetlands of the Southeastern United States.

Richter A, Kolmes S. 2005. Maximum temperature limits for Chinook, Coho and Chum salmon, and Steelhead Trout in the Pacific Northwest. Reviews in Fisheries Science, 13:23-49. 
Sauter S, McMillan J, Dunham J. 2001. Salmonid behavior and water temperature. EPA 910D-01-001.

Schlessinger W. 1997. Biogeochemistry. San Diego, CA: Academic Press.

Seybold C, Mersie W, Huang J, McNamme C. 2002. Soil redox, pH, temperature and water table patterns of a freshwater tidal wetland. Wetlands, 22(1):149-158.

Simenstad C, Bottom D [Internet]. 2002. Guiding Ecological Principles for Restoration of Salmon Habitat in the Columbia River Estuary. University of Washington, Seattle, WA. [Updated 2006 Sept 8; cited 2009 Sept 3]. Available from: www.fish.washington.edu/research/wet/publications/ecol_principles.doc

Simpson R, Good R, Leck M, Whigham D. 1983. The Ecology of Freshwater Tidal Wetlands. BioScience, 33(4):255-259.

Smith E, Orvos D, Cairns J. 1992. Impact assessment using the before-after-control-impact (BACI) model: Concerns and Comments. Canadian Journal of Fisheries and Aquatic Sciences, 50:627-637.

Smith, S [Internet]. 2007. Direct dam and reach survival. Science Policy Exchange; 2007 Sept 12-13; Portland OR, Northwest Power and Conservation Council. [Updated 2007; cited 2009 Sept 7]. Available from: http://www.nwcouncil.org/fw/program/2008amend/spe/agenda.htm

Stewart-Oaten A, Bence J, Osenber, C. 1986. Assessing Effects of Unreplicated Perturbations: No Simple Solutions. Ecology, 73(4):1396-1404.

Tanner D, Cordell J, Rubey J, Tear L. 2002. Restoration of freshwater intertidal habitat functions at Spencer Island, Everett, Washington. Restoration Ecology, 10:564-576.

Tonkin S [unreferenced]. 2009. Water temperature at Fisher Slough. Technical Memorandum by Moffatt \& Nichol, Seattle WA.

Tonnes D [Internet]. 2007. Fish use and water quality in select channels regulated by tide gates within the Snohomish River Estuary. West Coast Symposium on the Effects of Tide Gates on Estuarine Habitats and Fishes, Oct. 31-Nov. 2, 2006, Charleston, Oregon. [Updated 2006 Nov; cited 2009 Sept 3]. Available from: http://seagrant.oregonstate.edu/sgpubs/onlinepubs/w06001.pdf

Turner R, Lewis R. 1997. Hydrologic restoration of coastal wetlands. Wetlands Ecology and Management, 4(2):65-71.

Turner R. 2005. Evaluation of water quality in Gannon Slough before and after tide gate replacement. US Fish and Wildlife Service, Arcata, CA. 
Underwood A. 1992. Beyond BACI: the detection of environmental impacts on populations in the real, but variable world. Journal of Experimental Marine Biology and Ecology, 161:145-178.

[USACE] US Army Corps of Engineers. 2007. Draft integrated implementation report and environmental assessment. Julia Butler Hansen Columbian White-tailed Deer National Wildlife Refuge. US Fish and Wildlife Service, Julia Butler Hansen Wildlife Refuge, Cathlamet, WA.

[USGS] US Geological Survey [Internet]. National Water Information System. [Updated: 2009 Aug; cited 2009 Oct 2]. Available from: http://waterdata.usgs.gov/nwis/dv?referred_module=sw\&site_no=14246900.

Wetzel P, Kitchens W. 2007. Vegetation change from chronic stress events: detection of effects of tide gate removal and long term drought on a tidal marsh. Journal of Vegetation Science, 18:431-442.

Williams G, Zedler J. 1999. Fish assemblage composition in constructed and natural tidal marshes of San Diego Bay: relative influence of channel morphology and restoration history. Estuaries, 22(3):702-716.

Williams P, Orr M, Garrity N. 2002. Hydraulic geometry, a geomorphic design tool for tidal marsh channel evolution in wetland restoration projects. Restoration Ecology, 10(3): 577-590. 